\title{
Revisiting Vitis vinifera Subtilase Gene Family: A Possible Role in Grapevine Resistance against Plasmopara viticola
}

\author{
Joana Figueiredo 1, 2, 3 , Gonçalo J. Costa ${ }^{4}$, Marisa Maia ${ }^{1,2,3}$, Octávio S. Paulo ${ }^{4}$, Rui Malhó ${ }^{1}$, \\ Marta Sousa Silva ${ }^{2,3 * t}$ and Andreia Figueiredo ${ }^{1 * t}$ \\ ${ }^{1}$ Biosystems \& Integrative Sciences Institute, Faculdade de Ciências, Universidade de Lisboa, Lisboa, Portugal, ${ }^{2}$ Laboratório \\ de FTICR e Espectrometria de Massa Estrutural, Faculdade de Ciências, Universidade de Lisboa, Lisboa, Portugal, ${ }^{3}$ Centro \\ de Química e Bioquímica, Faculdade de Ciências, Universidade de Lisboa, Lisboa, Portugal, ${ }^{4}$ Computational Biology and \\ Population Genomics Group, Centre for Ecology, Evolution and Environmental Changes, Faculdade de Ciências, \\ Universidade de Lisboa, Lisboa, Portugal
}

OPEN ACCESS

Edited by:

Vincenzo Lionetti,

Sapienza University of Rome, Italy

Reviewed by:

Raffaella Balestrini,

National Research Council, Italy

Gabor Jakab,

University of Pécs, Hungary

*Correspondence:

Marta Sousa Silva

mfsilva@fc.ul.pt

Andreia Figueiredo

aafigueiredo@fc.ul.pt

${ }^{+}$These authors are co-senior authors in this paper.

Specialty section:

This article was submitted to

Plant Biotic Interactions,

a section of the journal

Frontiers in Plant Science

Received: 30 August 2016 Accepted: 11 November 2016 Published: 25 November 2016

Citation:

Figueiredo J, Costa GJ, Maia M, Paulo OS, Malhó R, Sousa Silva M and Figueiredo A (2016) Revisiting Vitis vinifera Subtilase Gene Family: A Possible Role in Grapevine Resistance against Plasmopara viticola.

Front. Plant Sci. 7:1783. doi: 10.3389/fpls.2016.01783
Subtilisin-like proteases, also known as subtilases, are a very diverse family of serine peptidases present in many organisms. In grapevine, there are hints of the involvement of subtilases in defense mechanisms, but their role is not yet understood. The first characterization of the subtilase gene family was performed in 2014. However, simultaneously, the grapevine genome was re-annotated and several sequences were re-annotated or retrieved. We have performed a re-characterization of this family in grapevine and identified 82 genes coding for 97 putative proteins, as result of alternative splicing. All the subtilases identified present the characteristic S8 peptidase domain and the majority of them also have a pro-domain 19 inhibitor, a protease-associated (PA) domain, and a signal peptide for targeting to the secretory pathway. Phylogenetic studies revealed six subtilase groups denominated VVSBT1 to VVSBT6. As several evidences have highlighted the participation of plant subtilases in response to biotic stimulus, we have investigated subtilase participation in grapevine resistance to Plasmopara viticola, the causative agent of downy mildew. Fourteen grapevine subtilases presenting either high homology to P69C from tomato, SBT3.3 from Arabidopsis thaliana or located near the Resistance to $P$. viticola (RPV) locus were selected. Expression studies were conducted in the grapevine-P. viticola pathosystem with resistant and susceptible cultivars. Our results may indicate that some of grapevine subtilisins are potentially participating in the defense response against this biotrophic oomycete.

Keywords: subtilases, Vitis vinifera, Plasmopara viticola, immunity, gene expression

\section{INTRODUCTION}

Subtilisin-like proteases (SBTs) are the second largest family of serine peptidases present in archaea, bacteria, eukarya, fungi, and yeast (Siezen et al., 1991). They belong to the S8 family within the SB clan of serine proteases, according to the classification of the peptidase database MEROPS (Rawlings et al., 2014; http://merops.sanger.ac.uk). The majority of plant subtilases are synthesized as an inactive pre-proprotein precursor. Their structure usually presents a signal peptide, a 
pro-domain (also known as I9 inhibitor domain), a subtilase domain (also known as S8 peptidase domain), and a proteaseassociated domain (PA), although some of them may have only one or even additional domains (Siezen and Leunissen, 1997; Dodson and Wlodawer, 1998; Antão and Malcata, 2005; Siezen et al., 2007; Vartapetian et al., 2011). The presence of a highly conserved catalytic triad within the S8 peptidase domain, composed by aspartate (Asp), histidine (His), and serine (Ser) amino acid residues is characteristic of the subtilase family (Dodson and Wlodawer, 1998). Additionally, certain subtilases may also have a conserved catalytic asparagine (Asn) residue in the same S8 peptidase domain (Siezen and Leunissen, 1997; Dodson and Wlodawer, 1998; Jordá et al., 1999). Furthermore, several plant subtilases also contain a fibronectin (Fn) III-like domain, required for their activation (Rawlings and Salvesen, 2013).

In opposition to mammals on which only nine subtilases have been identified, subtilases from plants are especially abundant, with 63 known genes in Oryza sativa (Tripathi and Sowdhamini, 2006), 56 genes in Arabidopsis thaliana (Rautengarten et al., 2005), 15 genes in Lycopersicon esculentum (Meichtry et al., 1999), 23 genes in the moss Physcomitrella patens, 90 genes in Populus trichocarpa (Schaller et al., 2012), and 82 genes in Solanum tuberosum (Norero et al., 2016). The expansion of the SBT family in plants was accompanied by functional diversification, and novel, plant-specific physiological roles were acquired in the course of evolution. In addition to their contribution to general protein turnover, plant SBTs are involved in the development of seeds and fruits, cell wall modification, processing of peptide growth factors, epidermal development, and pattern formation and in biotic and abiotic stress responses (reviewed in Schaller et al., 2012). In plant-pathogen interactions, the first evidences of subtilase participation were reported by Granell et al. (1987). This subtilase, named pathogenesisrelated protein 69 (P69), was later associated to the response of tomato leaves to Phytophothora infestans (Christ and Mösinger, 1989; Fischer et al., 1989) and characterized as an alkaline proteinase located in the vacuole and intercellular spaces of leaf parenchyma cells (Vera and Conejero, 1988; Vera et al., 1989; Tornero et al., 1997; Jordá et al., 1999, 2000; Meichtry et al., 1999). P69 was also the first plant subtilase for which two protein substrates were identified, systemin (Schaller and Ryan, 1994) and the leucine-rich repeat protein (LRP; Tornero et al., 1996), although the consequences of these substrates processing events for plant pathogen interaction still remain unknown. More recently, Ramírez and co-workers have identified a SBT3.3 gene from $A$. thaliana as encoding a serine protease homolog to the P69C subtilase from tomato and associated its function in immune priming responses (Ramírez et al., 2013). Also, in S. tuberosum, expression profile analysis of detached potato leaves after $P$. infestans infection or after BABA or BTH treatment highlighted an expression increase of several subtilases genes (Norero et al., 2016). Moreover, the subtilase St SBTc-3 has been found as a major protein in apoplast of detached potato leaves after $P$. infestans infection (Fernández et al., 2012) and it was shown that this subtilase evidences DEVDasa activity and is related to programmed cell death functions (Fernández et al., 2015).

In grapevine, the first clues highlighting subtilase participation defense mechanisms were reported by Figueiredo et al. (2008), when comparing resistant and susceptible genotypes prior and post-inoculation with Plasmopara viticola. A subtilisinlike protease (XM_010660203.1), identified as a cucumisin was constitutively expressed in resistant genotype and increased its expression after P. viticola inoculation (Figueiredo et al., 2008, 2012; Monteiro et al., 2013). Also in this pathosystem, it was shown that after treatment with serine protease inhibitors, plants became more sensitive to $P$. viticola (Gindro et al., 2012). It was hypothesized that some components of $P$. viticola secretome could inhibit the endogenous subtilases of susceptible varieties, thereby inhibiting the plant's normal defense reaction, while resistant or immune varieties may possess endogenous subtilases that are not recognized due to slight structural modifications of the protein patterns of these cultivars. In this case, plant defense mechanisms would continue to operate, with fatal consequences for the pathogen and restricting its development (Gindro et al., 2012).

In 2014, a first attempt to characterize the grapevine subtilase family was made by $\mathrm{Cao}$ and co-workers where the subtilase sequences were identified based on the presence of the PA domain (Cao et al., 2014). In parallel, a re-annotation of the grapevine genome was conducted (Vitulo et al., 2014) and several subtilase sequences were either re-annotated or retrieved. The aim of this work was to identify subtilisin-like proteases in the grapevine genome and characterize them based on phylogenetic analyses, gene and protein primary structure. Additionally, expression analysis of selected subtilase genes was conducted to identify subtilases potentially involved in downy mildew resistance.

\section{MATERIALS AND METHODS}

\section{Grapevine Subtilase Sequence Retrieval and Identification}

In order to identify members of the grapevine subtilase gene family, the amino acid sequence of the conserved domains PA (PF02225), S8 Peptidase (PF00082), and I9 Inhibitor (PF05922) were used as query for blast searches at NCBI (http://www.ncbi.nlm.nih.gov/) and MEROPS (Rawlings et al., 2014; https://merops.sanger.ac.uk/) databases (March, 2016).

\section{Domain Structure Analysis, Sequence Properties, and Subcellular Location Prediction}

SBT proteins domains and active sites were analyzed in Pfam (Finn et al., 2016; http://pfam.xfam.org/) and InterProScan (Jones et al., 2014; https://www.ebi.ac.uk/interpro/search/ sequence-search) databases (March, 2016); signal peptide was detected using the SignalP v4.1 (Petersen et al., 2011; http:// www.cbs.dtu.dk/services/SignalP/). Molecular weight (Mw) and theoretical isoelectric point $(\mathrm{pI})$ were predicted using the Protparam tool from ExPASy (Gasteiger et al., 2005; http://web. 
expasy.org/protparam/). Subcellular location of the subtilase proteins was predicted using TargetP v1.1 (Emanuelsson et al., 2000; http://www.cbs.dtu.dk/services/TargetP/) and PredoTar v1.3 (Small et al., 2004; https://urgi.versailles.inra.fr/predotar/ predotar.html).

\section{Chromosomal Location and Gene Structure}

The subtilase genes were mapped in $V$. vinifera chromosomes with the Map Viewer tool from NCBI (http://www.ncbi.nlm.nih. gov/mapview/) and the blast tool at Grape Genome Browser (http://www.genoscope.cns.fr/externe/GenomeBrowser/Vitis/).

Gene exon/intron structure information was collected from grapevine genome annotation at NCBI.

The physical map constructed with grapevine subtilases gene location was also compared to a genetic linkage map representing P. viticola resistance (RPV) QTLs in grapevine (Merdinoglu et al., 2003; Fischer et al., 2004; Wiedemann-Merdinoglu et al., 2006; Welter et al., 2007; Bellin et al., 2009; Marguerit et al., 2009; Blasi et al., 2011; Moreira et al., 2011; Schwander et al., 2011; Venuti et al., 2013; Ochßner et al., 2016) in order to access the location of grapevine subtilases within these loci.

\section{Phylogenetic Analysis}

Two phylogenetic analyses were carried out. The first one with all the identified grapevine subtilase amino acid sequences (97) and a second one combining these amino acid sequences with 56 SBTs amino acid sequences from $A$. thaliana (Rautengarten et al., 2005) and 14 from Solanum lycopersicum described in Meichtry et al. (1999).

Protein sequences were obtained from the NCBI database and aligned using the MAFFT software with the L-INS-i option (version 7, Katoh and Standley, 2013; http://mafft.cbrc. jp/alignment/software/), gaps were manually checked and edited in BioEdit v. 7.2.5 (Hall, 1999). A maximum likelihood (ML) phylogenetic analysis was performed with RAxML-HPC v.8, on CIPRES Science Gateway (Miller et al., 2010; https://www. phylo.org), with the following parameters: protein substitution model PROTCAT; protein substitution model + BLOSUM62; bootstrap 1000 iterations with rapid bootstrap analysis $(-\mathrm{f}$ a). Multiple alignment uncertainty was scored with ZORRO, assigning a confidence score for each column and applied as $(-\mathrm{a})$ option in RAxML-HPC v.8. Both trees were viewed on FIGTree (http://tree.bio.ed.ac.uk/software/figtree/) and edited on Inkscape (http://www.inkscape.org/).

\section{Selection of Grapevine Subtilase Sequences Putatively Involved in Pathogen Resistance}

Previous studies in plants associated some subtilases with the defense response to pathogen attack, like the subtilase SBT3.3 in A. thaliana (Ramírez et al., 2013), the P69 in S. lycopersicum (Tornero et al., 1996; Jordá et al., 1999) and the cucumisin in grapevine (Figueiredo et al., 2008, 2012). The subtilase genes from $V$. vinifera were blasted against the A. thaliana genome (TAIR database, https://www.arabidopsis.org/) and the tomato genome (SolGenomics database, https://solgenomics.net/) to retrieve the grapevine sequences presenting higher sequence similarity to A. thaliana SBT3.3 and tomato P69 genes. SolGenomics results were corroborated in NCBI BLAST tool, restricting to $S$. lycopersicum organism, and was assumed the NCBI accession for further studies. Moreover, subtilase sequences with a chromosomal location near the RPV locus on grapevine genome were also selected for further studies. Multiple alignment of the grapevine subtilases selected as putatively involved in plant resistance was performed in DNASTAR software (version 13, Burland, 1999; http://www.dnastar.com/).

\section{Gycosylation and Protein-Protein Interaction Network Predictions}

Protein glycosylation prediction was done using the NetNGlyc online server (version 1.0, Gupta and Brunak, 2002; http://www.cbs.dtu.dk/services/NetNGlyc/).

The protein interaction network of the selected subtilases was obtained (STRING, version 10.0, Szklarczyk et al., 2014; http://string-db.org/). The gene accessions for all proteins that interact with the selected grapevine subtilases were queried at the NCBI database. The gene ontology (GO) terms for all the interacting proteins were also obtained with the Blast2GO tool (version 3.3, Conesa et al., 2005; https://www.blast2go.com/).

\section{Experimental Design for Expression Analysis: Plant Material and Inoculation Experiments}

Two expression analysis experiments were conducted: (1) using two grapevine cultivars (resistant and susceptible) inoculated with $P$. viticola to access subtilase expression during inoculation; (2) using several grapevine accessions with different degrees of resistance toward $P$. viticola to access subtilase constitutive expression.

For the first analysis, two Vitis vinifera cultivars were selected to access subtilase expression during interaction with $P$. viticola. The cultivar Regent, bread by multiple introgressions from resistant wild genotypes (Welter et al., 2007), presenting a high degree of resistance to downy and powdery mildews (Anonymous, 2000), and Trincadeira, a Portuguese traditional grapevine cultivar widely used for quality wine production and highly sensitive to P. viticola (Figueiredo et al., 2008). Both cultivars were propagated under identical greenhouse conditions, briefly grapevine wood cuttings were grown in $12 \mathrm{~cm}$ diameter pots in Fruhstorfer Erde (soil) Type P for 10 weeks, under natural day/night rhythm with temperatures ranging between 5 and $28^{\circ} \mathrm{C}$, according to Figueiredo et al. (2012). For plant inoculation, $P$. viticola sporangia were collected after an overnight incubation of symptomatic leaves from greenhouse infected plants in a moist chamber at room temperature. Sporangia were carefully recovered by brushing, dried, stored at $-25^{\circ} \mathrm{C}$ and checked for their vitality by microscopy as in Kortekamp et al. (2008). A suspension containing $10^{4}$ sporangia $\mathrm{ml}^{-1}$ was used to spray the abaxial leaf surface in order to challenge the plants. Mock inoculations with water were also made. After inoculation, plants were kept in a 
moist chamber (100\% humidity) for $8 \mathrm{~h}$ and then under greenhouse conditions at $25^{\circ} \mathrm{C}$ during the inoculation time course. The third to fifth fully expanded leaves beneath the shoot apex were harvested at 6, 12, and 24 hpi, immediately frozen in liquid nitrogen and stored at $-80^{\circ} \mathrm{C}$. For each genotype and condition (inoculated and mock inoculated), three independent biological replicates were collected, being each biological replicate a pool of three leaves from three different plants.

For the second analysis, to access if subtilases are constitutively expressed, young leaves from several resistant (V. labrusca, V. rupestris, $V$. rotundifolia, $V$. riparia, and $V$. candicans) and tolerant (V. sylvestris) Vitis species and V. vinifera cultivars [Regent (resistant) and Trincadeira (susceptible)] were harvested from five different plants (per biological replicate), at the Portuguese Grapevine Germplasm Bank at INIA-Estação Vitivinícola Nacional (Dois Portos), (Supplementary Data 1). Leaves were immediately frozen in liquid nitrogen and stored at $-80^{\circ} \mathrm{C}$. Three biological replicates were collected from each accession.

\section{RNA Extraction and cDNA Synthesis}

Total RNA was isolated from frozen leaves with the Spectrum ${ }^{\mathrm{TM}}$ Plant Total RNA Kit (Sigma-Aldrich, USA), according to manufacturer's instructions. Residual genomic DNA was digested with DNase I (On-Column DNase I Digestion Set, SigmaAldrich, USA). RNA purity and concentration were measured at $260 / 280 \mathrm{~nm}$ using a spectrophotometer (NanoDrop-1000, Thermo Scientific) while RNA integrity was verified by agarose gel electrophoresis (1.2\% agarose in TBE buffer). Genomic DNA (gDNA) contamination was checked by qPCR analysis of a target on the crude RNA (Vandesompele et al., 2002). Complementary DNA (cDNA) was synthesized from $2.5 \mu \mathrm{g}$ of total RNA using RevertAid ${ }^{\circledR} \mathrm{H}$ Minus Reverse Transcriptase (Fermentas, Ontario, Canada) anchored with Oligo $(\mathrm{dT})_{23}$ primer (Fermentas, Ontario, Canada), according to manufacturer's instructions.

\section{Quantitative Real Time PCR}

Quantitative RT-PCR (qPCR) experiments were carried out using Maxima $^{\mathrm{TM}}$ SYBR Green $\mathrm{qPCR}$ Master Mix $(2 \times)$ kit (Fermentas, Ontario, Canada) in a StepOne ${ }^{\mathrm{TM}}$ Real-Time PCR system (Applied Biosystems, Sourceforge, USA). A final concentration of $2.5 \mathrm{mM} \mathrm{MgCl}_{2}$ and $0.2 \mu \mathrm{M}$ of each primer were used in $25 \mu \mathrm{L}$ volume reactions, together with $4 \mu \mathrm{L}$ of cDNA as template. Primer sequences and reaction details are provided in Supplementary Data 2.

Thermal cycling for all genes started with a denaturation step at $95^{\circ} \mathrm{C}$ for $10 \mathrm{~min}$ followed by 40 cycles of denaturation at $95^{\circ} \mathrm{C}$ for $15 \mathrm{~s}$ and annealing (Supplementary Data 2) for $30 \mathrm{~s}$. Each set of reactions included a control without cDNA template. Dissociation curves were used to analyse non-specific PCR products. Three biological replicates and two technical replicates were used for each sample. Gene expression (fold change) was calculated by the Hellemans et al. (2007). The reference genes used for the normalization were the previously described in Monteiro et al. (2013). Statistical significance $(p<$
0.05) of gene expression was determined by the Mann-Whitney U test using IBM ${ }^{\circledR}$ SPSS ${ }^{\circledR}$ Statistics version 23.0 software (SPSS Inc., USA).

\section{RESULTS AND DISCUSSION}

\section{Identification and Characterization of Subtilisin-Like Serine Protease Genes in Grapevine}

The first characterization of the grapevine subtilase family was made by Cao and co-workers in 2014, where 80 subtilase genes were identified (Cao et al., 2014). Subtilase search was restricted to the subtilase conserved PA domain, although subtilases are usually characterized by three conserved domains (PA, S8 peptidase and 19 inhibitor). In parallel, the grapevine genome was re-annotated (Vitulo et al., 2014), nine of the previously identified genes were completely removed from the databases and eight were re-annotated. Thus, we have performed a new characterization of this family in grapevine using the subtilase PA, S8 peptidase and I9 inhibitor domains as query in the new grapevine genome annotation version. Eighty-two $V$. vinifera subtilase genes were identified, from which it is predicted to obtain 97 subtilase proteins (Supplementary Data 3). This search resulted in the introduction of 17 new subtilase genes and the re-annotation of 8 from the subtilase genes previously identified (Cao et al., 2014). The number of genes members found in $V$. vinifera subtilase family is similar to the one from $P$. trichocarpa (90 subtilase genes; Schaller et al., 2012) and potato (82 subtilase genes; Norero et al., 2016) and higher than those reported in other plant species, like Arabidopsis or tomato, which were detected 56 and 15 subtilase genes, respectively (Meichtry et al., 1999; Rautengarten et al., 2005).

The 82 identified genes identified were mapped in $V$. vinifera chromosomes. These genes were unevenly distributed among 15 of the 19 grapevine chromosomes (Figure 1). No subtilase genes were detected on chromosomes $1,5,14$, and 17 , and the specific location of 8 of the 82 subtilase genes is still unknown. The majority of the subtilase genes were located on chromosomes 6 , 13, and 16, with 9 genes in chromosome 6 and 10 in chromosomes 13 and 16 (Figure 1).

\section{Gene Structure Analysis}

Grapevine STB genes were checked for exon-intron structure. Details of the exon-intron structures are shown in Supplementary Data 3. The number of introns varied between 0 and 18 , around $24 \%$ of the grapevine subtilase genes are intronless and $5 \%$ present a high number of introns (17-18 introns). Intronless subtilase genes have been reported in Arabidopsis and potato (Rautengarten et al., 2005; Norero et al., 2016) being the highest number of introless genes reported in potato $(63 \%$ of the StSBT genes; Norero et al., 2016). Intronless genes can serve as beacons in analyses of gene function and evolution, they have been found in large gene families and related to gene duplications, inheritance from ancient prokaryotes, retroposition or other mechanisms (Yan et al., 2016). In general, most closely related 


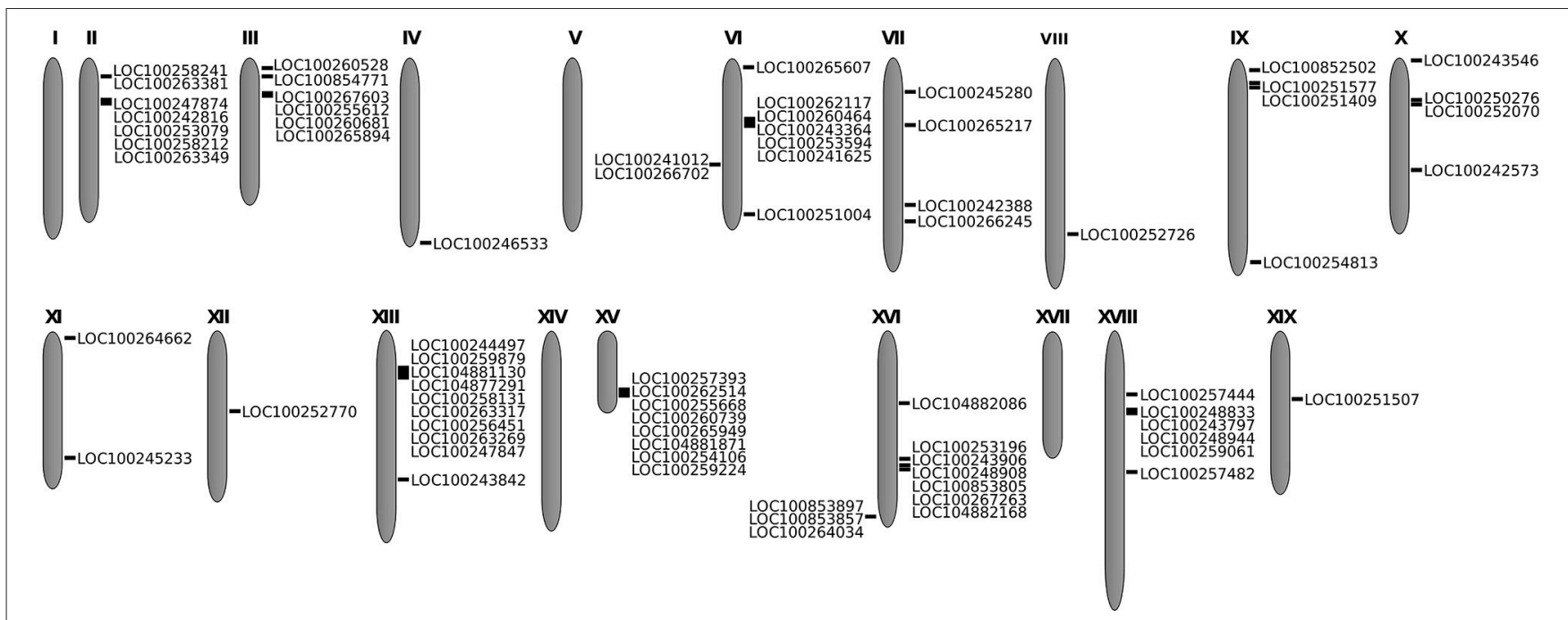

FIGURE 1 | Location of the $\mathbf{8 2}$ subtilase genes in the grapevine chromosomes. In each illustrated chromosome, subtilase gene accession is shown.

members in the same group shared a similar exon-intron structure.

\section{Protein Structure and Domain Analysis}

Both molecular weight $(\mathrm{Mw})$ and isoelectric point (pI) were predicted for the grapevine subtilase proteins (Supplementary Data 3). V. vinifera subtilase proteins have a wide range of molecular weights, between 19 and $164 \mathrm{kDa}$, slightly higher than the already described for other plant serine proteases (between 19 and $110 \mathrm{kDa}$; Antão and Malcata, 2005). The majority $(60 \%)$ present a theoretical molecular weight between 80 and $90 \mathrm{kDa}$, and only $26 \%$ between 60 and $80 \mathrm{kDa}$ as previously described for other plant serine proteases (Antão and Malcata, 2005). The remaining $14 \%$ presented a molecular weight lower than $60 \mathrm{kDa}$ or higher than $90 \mathrm{kDa}$. Grapevine subtilases have a theoretical pI between 4.69 and 9.57. This $\mathrm{pI}$ range is comparable to other subtilase proteins, like, for example the STB3.3 (AT1G32960.1) from A. thaliana and P69C (CAA76726) from tomato with a theoretical pI of 6.27 and 5.27, respectively (predicted from protein sequence with Compute pI/Mw tool from ExPASy, http://web.expasy.org/compute_pi/) or the CPSUB1 from papaya with a pI of 8.97 (Othman and Nuraziyan, 2010).

Subtilases are characterized by a multidomain structure comprising a signal peptide, a propeptide, a protease domain (S8) and a protease-associated (PA) domain (Siezen et al., 2007). The protease domain ( $\mathrm{S} 8$ domain) that defines the subfamily S8A (PF00082), includes the catalytic triad and a proteaseassociated domain (PA) (PF02225) which is an insertion of about 120-160 amino acids long between the His and Ser active site residues that cause a displacement of the reactive Ser from the catalytic triad to the C-terminal (Siezen and Leunissen, 1997). This domain has been implicated in protein-protein interactions or substrate specificity (Siezen and Leunissen, 1997). All of the 97 grapevine subtilases identified present the
S8 domain (Supplementary Data 3) and 6 subtilase sequences have S8 domain duplication (Supplementary Data 3). Ninety of the VvSBTs presented the I9 inhibitor domain and the same sequences that contained S8 domain duplication also presented duplication of the I9 domain (Supplementary Data 3). This I9 inhibitor domain (PF05922), also known as pro-domain $\mathrm{N}$ terminus or propeptide, is involved after removal, on the pro-enzyme activation, working as a molecular chaperone in the folding of the mature peptidase. Thus, the I9 inhibitor prevents the access of the substrate to the active site and activates the peptidase when it is removed either by autocatalytic cleavage or by interaction with a secondary peptidase (Siezen, 1996). The PA domain was detected in all of the subtilase sequences, but only in 46 sequences the Evalue was considered significant $(E \leq-5)$. On the other 39 sequences the presence of the PA domain presents low $\mathrm{E}$ values or is listed as unintegrated signature. However, the shift on the reactive Ser from the catalytic triad to the C-terminal is present in all of the grapevine subtilase sequences, which may suggest sequence divergence for this domain.

Not all the grapevine subtilases exhibited the three domains simultaneously. Despite being conserved in plant subtilases, the simultaneous presence of I9 inhibitor, S8 peptidase, and PA domain is not obligatory requisite. Moreover, it is yet to be confirmed if the simultaneous presence or not of this set of domains has some effects in subtilase functions. An example of the non-simultaneous existence of the three conserved domains is the P69C subtilase from tomato (Tornero et al., 1997).

The presence of subtilases with domain repeats can be a result of the evolution and a way to improve the subtilase features and its functions. Gene duplication and mutation processes in biological evolution have been largely recognized since the 1930s (Bridges, 1936; Brown and Doolittle, 1995; Zhang, 2003). Gene duplication may result in domain repeats in 
protein structure. These repeats have a rich variety of functional properties involving protein-protein interactions as well as binding to other molecules like DNA or RNA. Furthermore, long tandem of repeats can play an important role in the folding of three dimensional structures of multi-domain proteins. Structural studies in proteomics have shown that the abundance of domain repeats in organisms of higher complexity is highly correlated with domain families involved in complexassembly, cell-adhesion, and signaling processes (Han et al., 2007).

Six $V v$ SBT presented an additional domain, the fibronectin (Fn) III-like domain (PF06280), (Supplementary Data 3). This domain of unknown function is required by some plant subtilases for their activity (Rawlings and Salvesen, 2013). The SBT3.3 subtilase structure from $A$. thaliana showed the presence of the three conserved domains and also a fibronectin (Fn) III-like domain (Rose et al., 2010).

\section{Subcellular Location Prediction}

Predictions of the subcellular location of a gene product can provide additional information for its functional involvement. Different subcellular locations of plant subtilases have been found to correlate with their different physiological functions (Rautengarten et al., 2005; Cao et al., 2014). For example, the CPSUB1 subtilase from papaya is secreted to extracellular space, where it plays a role in the early stage of fruit development and ripening by degrading cell wall matrix (Othman and Nuraziyan, 2010). Rice subtilase RSP1 is only present in the reproductive organ and absent in leaves, roots, embryos, or rice panicles (Yoshida and Kuboyama, 2001). This suggests that the role for each plant subtilase is related to its location event in spite of analogous structural features (Othman and Nuraziyan, 2010). Sixty VvSBTs possess signal sequences for targeting to the secretory pathway (S), 26 subtilases do not contain any known targeting motif, 8 family members are predicted to be targeted to mitochondria (M) and 3 to the chloroplast (C), (Supplementary Data 4). Hence, grapevine subtilases may have a diversity of functions, most of them probably with roles in the extracellular space or matrix.

\section{Phylogenetic Analysis of Grape Subtilases}

A phylogenetic analysis of the 97 grapevine subtilase proteins was carried out and the consensus phylogeny obtained is shown in Figure 2. Based on the phylogenetic relationships of the grapevine subtilases proteins found, an outgroup was identified and 6 SBT groups were established and named $V v$ SBT1 to $V v$ SBT6 (Figure 2). $V v \mathrm{SBT} 1$ comprise 23 subtilases and include all the subtilases annotated as cucumisin (degradative subtilases from Cucumis melo). VvSBT1 coding genes are unevenly distributed among grapevine chromosomes and present a structure with variable number of introns (Supplementary Data 3). VvSBT2 is the smallest group containing 4 subtilase proteins annotated as xylem serine proteins. All of the coding genes present a 10 intron structure and are distributed between chromosome 8 and 15 (Supplementary Data 3 ). The $V v$ SBT3 group comprises 14 subtilases proteins, most of them presenting similarity with
A. thaliana SBT3.3/SBT3.5 proteins. All of the coding genes present more than 9 introns and an uneven chromosomal location (Supplementary Data 3). VvSBT4 includes 13 subtilase proteins, most of them showing similarity to $A$. thaliana SBT5.3/SBT5.4. Within this group subtilase coding genes present between 5-10 introns and for most of the genes the chromosomal location is unknown (Supplementary Data 3). $V v$ SBT5 is the largest group including 34 subtilase proteins that are annotated as subtilisin-like proteins. Within this group, most of the coding genes are intronless or present 1-2 intron. $V v$ SBT6 is comprised by 6 subtilase proteins all containing an additional fibronectin III-like domain, the coding genes are all located in chromosome 11 and present 13 introns (Supplementary Data 3). Rautengarten and co-workers have equally performed a phylogenetic analysis of the predicted 56 A. thaliana (AtSBT) subtilase sequences that showed a division of the subtilases into 6 groups (Rautengarten et al., 2005). In potato, 5 subtilase groups were considered (Norero et al., 2016).

\section{Phylogenetic Analysis of Grapevine, Tomato, and Arabidopsis Subtilases}

Biological functions of plant subtilases remain largely unknown. The phylogenetic analysis of 168 amino acid sequences including grapevine, tomato and Arabidopsis subtilases evidenced 8 clusters named from I to VIII (Figure 3).

Cluster I consists in all the tomato subtilase proteins, and all members from the AtSBT1 and VvSBT5 groups. In this cluster grapevine subtilase proteins XP_010662319.1, XP_002275410.2, XP_002275429.1, XP_002275381.2, XP_002275471.2 are closely related to tomato $\mathrm{P} 69$ genes already described as being associated to biotic stress responses (Granell et al., 1987; Vera and Conejero, 1988; Christ and Mösinger, 1989; Fischer et al., 1989; Vera et al., 1989; Tornero et al., 1997; Jordá et al., 1999, 2000; Meichtry et al., 1999). XP_010652423.1 is the homolog of Arabidopsis SDD1 (stomatal density and distribution 1 protease) involved in the regulation of stomata distribution and density during leaf development (Von Groll et al., 2002) and XP_002284101.1, XP_002283279.2 could be related to Arabidopsis ARA12 that participates in seed germination (Rautengarten et al., 2008).

Cluster II includes the grapevine VvSBT6 group, the three subtilase sequences considered as an outgroup (Figures 2, 3) and the AtSBT2 group (which included the ALE1 protease necessary for cuticle formation and epidermal differentiation during embryo development in A. thaliana (Tanaka et al., 2001).

Cluster III comprises the AtSBT3 group including the AtSBT3.3 recently described as being involved in immune priming events in Arabidopsis (Ramírez et al., 2013) and several proteins from the $V v \mathrm{SBT} 3$ group (Figure 2).

Cluster IV groups the grapevine $V v S B T 4$ group and the AtSBT5.3, AtSBT5.4, AtSBT5.5, AtSBT5.6, AtSBT6.1, and AtSBT6.2 subtilases. The grapevine XP_010657502.1, member of the $V v$ SBT4 group appears closely related to the AtSBT5.3 is encoded by the AIR3 involved on lateral root formation (Neuteboom et al., 1999). Another member of $V v$ SBT4, the subtilase XP_002269375.1, is also closely related to Arabidopsis 


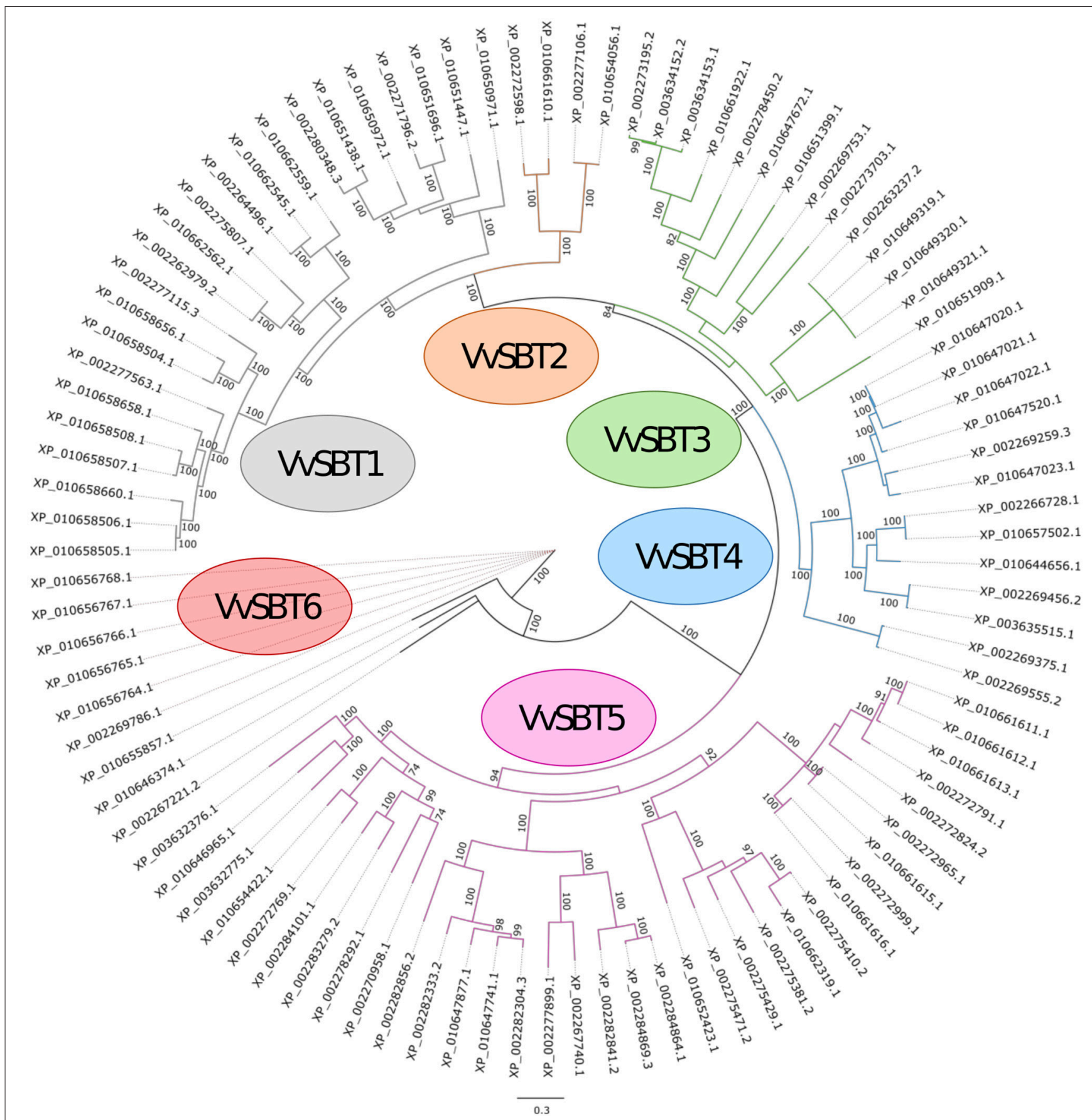

FIGURE 2 | Maximum likelihood phylogenetic tree of the 97 subtilisin-like serine proteases from Vitis vinifera. The six groups are shown (VVSBT1-VVSBT6) and three sequences were defined as outgroup (XP_010655857.1, XP_010646374.1, and XP_002267221.2). The numbers above branches show bootstrap values. Scale bar represents the number of estimated changes per branch length.

SBT6.1 which is involved in the unfolded protein response through the cleavage of an ER-resident type II membrane protein (bZIP28; Liu et al., 2007; Che et al., 2010; Liu and Howell, 2010a,b).

Cluster V includes two grapevine subtilases from SBT3 group, both named $\mathrm{CO}(2)$-response secreted protease and two AtSBT subtilases, AtSBT5.1 and 5.2, suggesting that these subtilases may share common functions.

Cluster VI groups the VvSBT2 group and the AtSBT4.14 and SBT4.15 involved in the xylem differentiation (Zhao et al., 2000).

Cluster VII is defined by the remaining members of the AtSBT4 group and seven grapevine subtilases from the $V v \mathrm{SBT} 1$ 


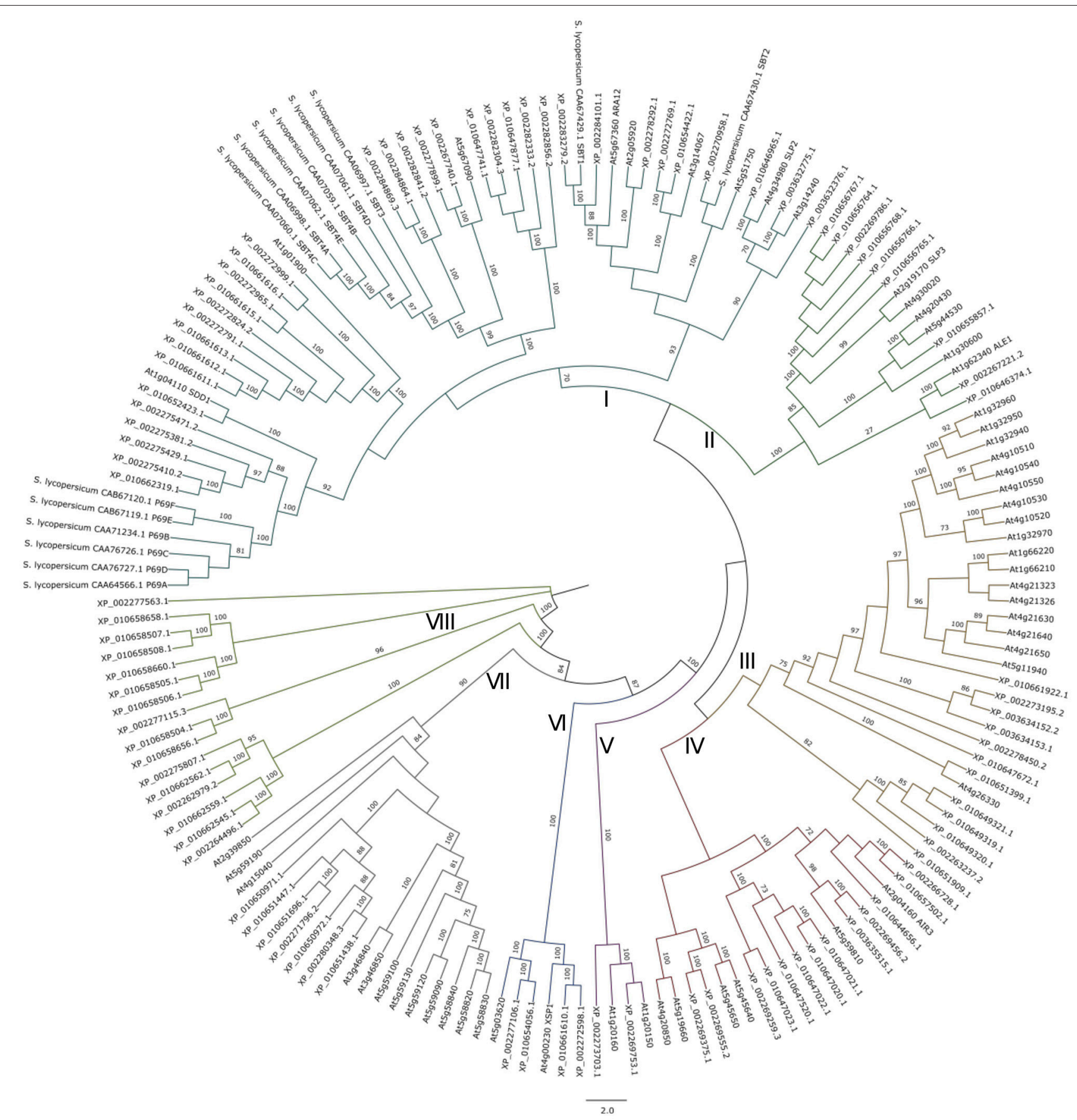

FIGURE 3 | Maximum likelihood phylogenetic tree of 97 subtilisin-like serine protease proteins from Vitis vinifera, 14 from Solanum lycopersicum, and 56 from Arabidopsis thaliana. Eight clusters named from I to VIII are shown. The numbers above branches show bootstrap values. Scale bar represents the number of estimated changes per branch length.

group, all presenting the coding genes located in chromosome 6 (Supplementary Data 3).

Clusters VIII includes all of the remaining sequences from the $V v$ SBT1 group, being located in chromosome 16 and 13, respectively. These $V v \mathrm{SBT}$ could have evolved separated from Arabidopsis subtilases.

\section{Selection of Subtilases Putatively Involved in Grapevine Immunity}

The subtilases SBT3.3 from A. thaliana and P69 from tomato are by far the most studied and associated to defense responses to pathogen attack (Tornero et al., 1997; Jordá et al., 1999; Ramírez et al., 2013). Tomato P69 subtilases present at least 
six closely related genes (P69A to P69F; Tornero et al., 1997; Jordá et al., 1999, 2000; Meichtry et al., 1999), but only P69B and $\mathrm{P} 69 \mathrm{C}$ were shown to behave as pathogenesis-related (PR) genes being induced by pathogen infection and salicylic acid (Tornero et al., 1997; Jordá et al., 1999). A. thaliana SBT3.3 is the only subtilase associated to defense mechanisms, this subtilase gene is embedded in a genomic cluster encompassing three additional subtilases (SBT3.5, SBT3.4, and SBT3.2; Ramírez et al., 2013). Also, our previous studies have highlighted the potential involvement of a subtilase (XM_010660203.1) in the defense response of grapevine against the biotrophic oomycete P. viticola (Figueiredo et al., 2008, 2012; Monteiro et al., 2013). Along with this subtilase, we have selected several grapevine subtilases putatively involved in the defense against $P$. viticola for expression studies (Table 1) based on their sequence identity (higher than 50\%) with AtSBT3.3 and the tomato P69C (XM_002273159.3, XM_002275345.2, XM_002275374.2, XM_002275393.2, XM_002275435.2, XM_002278414.3, XM_ 003634104.2, XM_003634105.2, XM_010649370.1, XM_ 010663620.1).

Several grapevine chromosomal locus associated with the resistance to $P$. viticola (named "Resistance to P. viticola"RPV) have been identified (Merdinoglu et al., 2003; Fischer et al., 2004; Wiedemann-Merdinoglu et al., 2006; Welter et al., 2007; Bellin et al., 2009; Marguerit et al., 2009; Blasi et al., 2011; Moreira et al., 2011; Schwander et al., 2011; Venuti et al., 2013; Ochßner et al., 2016). Chromosomal location of the previously identified grapevine subtilase genes was compared with the location of the known RPV's in V. vinifera chromosomes (Table 2). Three subtilase genes were selected: XM_002277863.3 and XM_002284065.3 located at 16.7 and $15.7 \mathrm{Mb}$ (within the $R p v 9$ in chromosome 7) and XM_010659200.1 located at $10.2 \mathrm{Mb}$ between two RPV's, (Rpv1 situated at $10.3 \mathrm{Mb}$ and Rpv13 placed at $10.0 \mathrm{Mb}$ in chromosome 12; Table 2).

The 14 selected grapevine subtilases potentially linked to $V$. vinifera immunity were further analyzed. A prediction of glycosylated sites was performed in the selected grapevine proteins (Table 3) as it has been shown that glycosylated plant subtilases are secreted to plant extracellular matrix (ECM; Bykova et al., 2006; Cedzich et al., 2009). Since the ECM is where the first host-pathogen interaction, recognition and signaling events take place (Dixon and Lamb, 1990), the accumulation of subtilases in plant ECM may account for an important role during pathogenesis. The most important protein glycosylation form is $\mathrm{N}$-linked, formed by the covalent attachment of asparaginelinked carbohydrates to the protein (Gupta and Brunak, 2002; Bykova et al., 2006). Protein $\mathrm{N}$-glycosylation was previously described in subtilases P69B from tomato (Bykova et al., 2006). From the 14 protein sequences analyzed, only two may not contain a signal peptide (XM_002275345.2, XM_010659200.1), and thus may not be glycosylated in vivo, even though they contain potential motifs. The remaining 12 proteins seem to contain a signal peptide and $\mathrm{N}$-glycosylation was predicted in several Asp residues (Table 3).

The protein-protein interaction network for the selected subtilases putatively involved in grapevine immunity was performed. By understanding the protein environment where these proteins are likely involved, it is feasible to obtain relevant information about their function and the biological processes. For this analysis, the STRING database was used (Szklarczyk et al., 2014). The top 50 proteins that interact with the 14 grapevine subtilases were analyzed individually in UniProt to access the biological processes to which they are associated. Five of these proteins were predicted to interact with all of the selected grapevine subtilases and are involved in biological processes associated to defense responses, namely fatty acid beta-oxidation, protein kinase activity, ER-associated ubiquitin-dependent protein catabolic process, defense response and protein serine/threonine kinase activity (Supplementary Data 5). Lipid peroxidation and lipidassociated signaling have been recently associated to grapevine resistance to P. viticola (Figueiredo et al., 2015; Guerreiro et al., 2016). Also protein kinases are known to regulate the majority of cellular pathways, especially those involved in signal transduction (Dhanasekaran and Premkumar Reddy, 1998). This proteinprotein interaction network result reinforces the hypothesis that these 14 subtilases may have some involvement in the grapevine immunity.

\section{Expression Analysis}

Expression profiles of the selected grapevine subtilases were first analyzed in two $V$. vinifera cultivars, Regent and Trincadeira (resistant and susceptible to $P$. viticola, respectively) at 6,12 and $24 \mathrm{~h}$ after inoculation (hpi) with P. viticola. Early inoculation time points were chosen to access the signaling events during pathogen recognition: between 6 and 12 hpi stomatal penetration and development of stomatal vesicles with primary hyphae occurs and at 24 hpi elongated hyphae invade the intercellular space of the mesophyll progressing to the branching stage in susceptible plants and stopping the development in resistant plants (Kortekamp and Zyprian, 2003; Unger et al., 2007).

Of the 14 grapevine subtilases analyzed, two presented no amplification (XM_002275393.2: sequence similarity with P69C and XM_002277863.3: located in rpv9) in both cultivars and were retrieve from our study. Three subtilases that present either sequence homology with AtSBT3.3 (XM_003634104.2 and XM_002273159.3) or are located in the rpv loci (XM_010659200.1) presented the same expression pattern during inoculation time-course in the resistant cultivar Regent, being up-regulated at $6 \mathrm{hpi}$, decreasing their expression at $12 \mathrm{hpi}$ and increasing again at $24 \mathrm{hpi}$ (Figure 4). In the susceptible genotype, these subtilases were more expressed at $24 \mathrm{hpi}$ (Figure 4). Also, the subtilase XM_003634105.2 (presenting sequence homology with AtSBT3.3) showed an up-regulation at the early time-points analyzed (6 and $12 \mathrm{hpi}$ ) in the resistance cultivar Regent, being down-regulated at 24 hpi. In the susceptible cultivar Trincadeira, this gene was down-regulated at $6 \mathrm{hpi}$ and increased its expression from $12 \mathrm{hpi}$ (Figure 4). Accordingly, in Vitis pseudoreticulata leaves infected with the biotrophic ascomycete Erysiphe necator (Schw.) Burr., presented an up-regulation of all these subtilase genes after infection (Weng et al., 2014).

The grapevine subtilase gene XM_010649370.1, showing homology with AtSBT3.3, exhibited an increase of expression 
TABLE 1 | Grapevine subtilase proteins presenting sequence similarity with SBT3.3, SBT3.5, and P69C from Arabidopsis thaliana and Solanum lycopersicum.

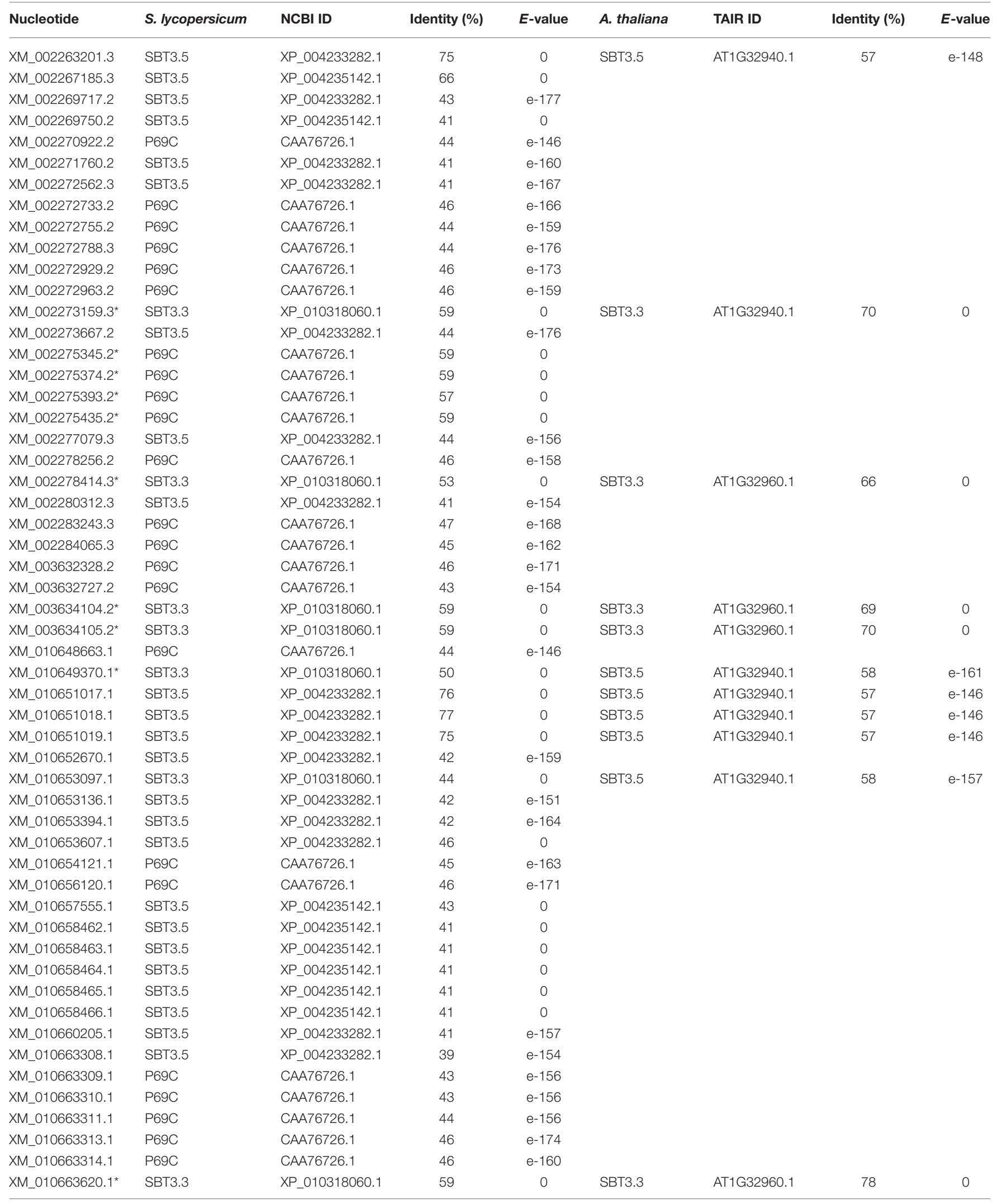

Gene identification, sequence identity (\%) and E-value are indicated. Asterisk (*) indicate subtilases selected for further studies. 
TABLE 2 | Traits and allelles associated with Vitis resistance to Plasmopara viticola.

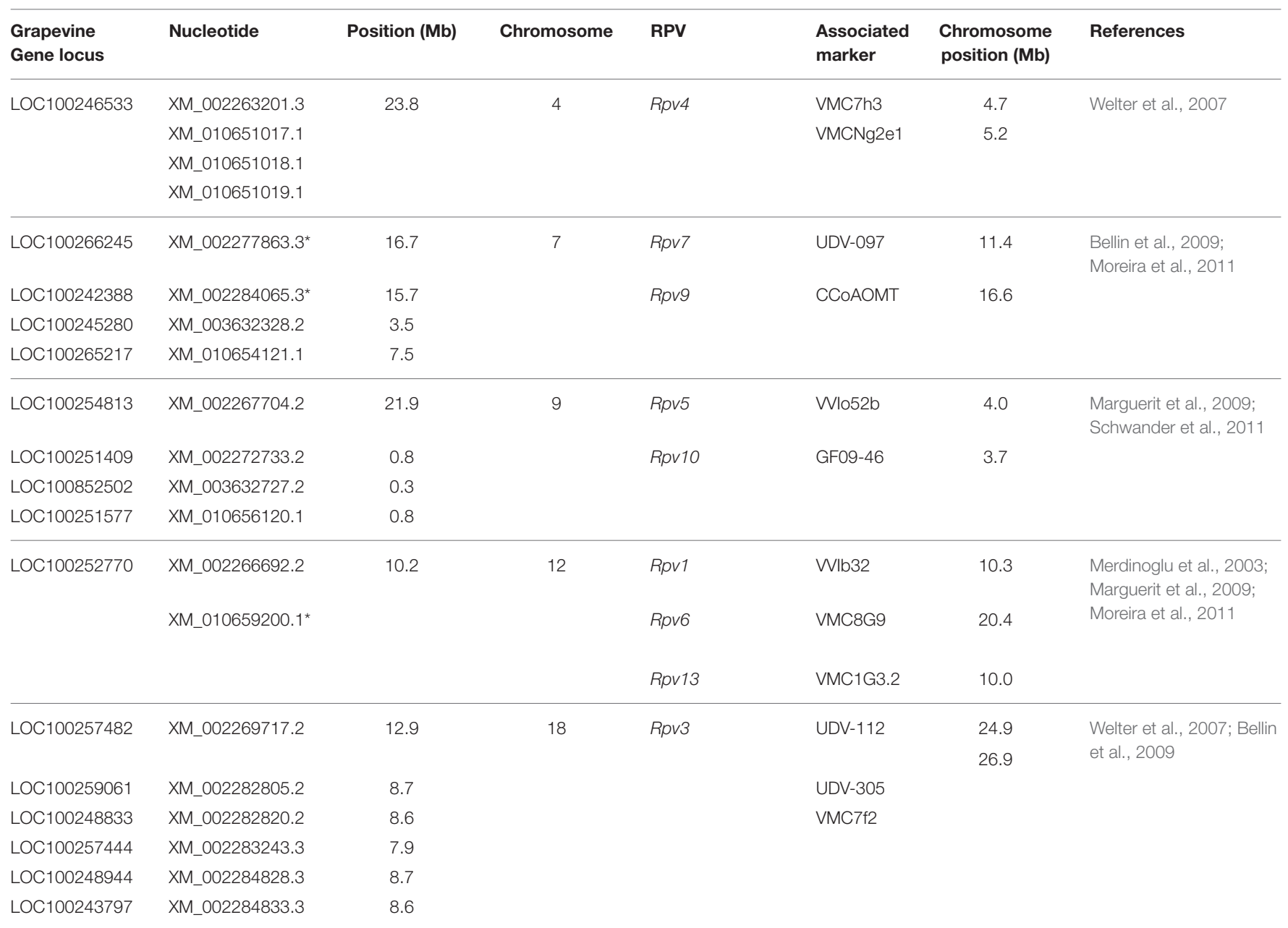

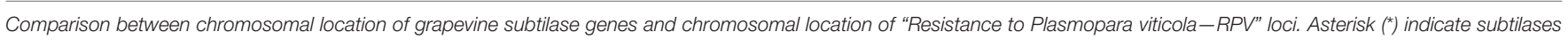
selected for further studies.

at both 6 and $24 \mathrm{hpi}$, being down-regulated at $12 \mathrm{hpi}$, in the resistant cultivar, while in the susceptible cultivar this gene is over-expressed during all the inoculation time-course (Figure 4). The expression of this subtilase has been previously analyzed in different grapevine tissues and abiotic stimuli (Cao et al., 2014), exhibiting a constitutive high-level of expression in roots, leaves, and stem and the expression was supressed in abiotic (salt, heat, cold, and drought) stress conditions (Cao et al., 2014), which may suggest that it could have a participation in response to biotic stimulus instead. Recently, a Gossypium babardense subtilase gene GbSBT1, that show a high sequence homology with the grapevine subtilase XM_010649370.1, was associated with the defense response to extracellular stimulations like Verticillium dahlia infection, the cause of the Verticillium wilt disease. The corresponding GbSBT1 protein showed to be mainly localized at the cell membrane and moves to the cytoplasm following treatment with jasmonic acid and ethylene, which supports the hypothesis of some grapevine subtilases are located near the place where occurs the plant-pathogen interaction. Moreover, Duan and co-workers, observed a reduction of the tolerance of a cotton resistant genotype, when the GbSBT1 gene was silenced, and an activation of the expression levels of defense-related genes (Duan et al., 2016).

Two subtilases presenting sequence homology with AtSBT3.3 (XM_010663620.1) and located at the rpv9 (XM_002284065.3) showed a similar expression pattern, being up-regulated at the later time-point analyzed ( $24 \mathrm{hpi}$ ) in the resistant cultivar Regent, however in the susceptible cultivar Trincadeira both genes have an earlier and higher expression starting at $12 \mathrm{hpi}$. The expression of the subtilase XM_002284065.3 was also analyzed by Cao and co-workers and an increase of expression during abiotic stress was shown (Cao et al., 2014). Both results suggest an involvement of this subtilase in response to abiotic and biotic environmental stimulus.

The expression of XM_002278414.3 (presenting homology with AtSBT3.3) and XM_002275435.2 (presenting homology with tomato P69C) was either not altered or down-regulated during inoculation time-course in both cultivars (Figure 4). Accordingly this subtilase presented low when submitted to abiotic stress conditions (heat and drought; Cao et al., 2014). 
TABLE 3 | Signal peptide, N-glycosylation, and subcellular location prediction for the subtilases putatively involved in grapevine immunity.

\begin{tabular}{|c|c|c|c|c|c|c|c|}
\hline Nucleotide & $\begin{array}{l}\text { Sequence } \\
\text { identification } \\
\text { (NCBI) }\end{array}$ & $\begin{array}{l}V v S B T \\
\text { group }\end{array}$ & $\begin{array}{l}\text { Chromosomal } \\
\text { location }\end{array}$ & selection & $\begin{array}{l}\text { Signal peptide } \\
\text { prediction, signalP } \\
4.1 \text { (position) }\end{array}$ & $\begin{array}{l}\mathrm{N} \text {-glycosylation } \\
\text { prediction } \\
\text { (Asn-X-Ser/Thr), } \\
\text { NetNGlyc } 1.0 \text { Server } \\
\text { (position and sequence) }\end{array}$ & $\begin{array}{l}\text { Subcellular } \\
\text { location } \\
\text { prediction }\end{array}$ \\
\hline XM_002273159.3 & $\begin{array}{l}\text { Subtilisin-like } \\
\text { protease SBT3.5 }\end{array}$ & VvSBT3 & 16 & $\begin{array}{l}\text { Similarity to } \\
\text { AtSBT3.3 }\end{array}$ & YES (1-27) & $\begin{array}{l}\text { YES } \\
(184 \text { NAT) } \\
(212 \text { NTT) } \\
(373 \text { NRT) } \\
\text { (385 NHT) } \\
\text { (412 NDT) } \\
\text { (646 NNS) } \\
\text { (682 NST) } \\
\text { (689 NVT) } \\
\text { (697 NST) }\end{array}$ & $\begin{array}{l}\text { Extracellular } \\
\text { region }\end{array}$ \\
\hline XM_002275374.2 & $\begin{array}{l}\text { Subtilisin-like } \\
\text { protease SDD1 }\end{array}$ & VvSBT5 & 2 & $\begin{array}{l}\text { Similarity to } \\
\text { P69C }\end{array}$ & YES (1-31) & $\begin{array}{l}\text { YES } \\
\text { (137 NRS) } \\
\text { (186 NGT) } \\
\text { (366 NFS) } \\
\text { (382 NQT) } \\
\text { (526 NVT) } \\
\text { (644 NCS) }\end{array}$ & $\begin{array}{l}\text { Apoplast; } \\
\text { Plant-type cell } \\
\text { wall }\end{array}$ \\
\hline XM_002275435.2 & $\begin{array}{l}\text { Uncharacterized } \\
\text { protein } \\
\text { LOC100242816 }\end{array}$ & VvSBT5 & 2 & $\begin{array}{l}\text { Similarity to } \\
\text { P69C }\end{array}$ & YES (1-31) & $\begin{array}{l}\text { YES } \\
\text { (254 NGT) } \\
\text { (338 NGS) } \\
\text { (398 NAS) } \\
\text { (542 NDT) } \\
\text { (656 NRT) } \\
\text { (699 NSS) } \\
\text { (1053 NTT) } \\
\text { (1196 NST) }\end{array}$ & $\begin{array}{l}\text { Apoplast; } \\
\text { Plant-type cell } \\
\text { wall }\end{array}$ \\
\hline XM_002277863.3 & $\begin{array}{l}\text { Subtilisin-like } \\
\text { protease }\end{array}$ & vvSBT5 & 7 & Rpv9 & YES (1-23) & $\begin{array}{l}\text { YES } \\
(184 \text { NFT) } \\
\text { (216 NSS) } \\
\text { (247 NGT) } \\
\text { (298 NNS) } \\
\text { (421 NAT) }\end{array}$ & $\begin{array}{l}\text { Apoplast; } \\
\text { Plant-type cell } \\
\text { wall }\end{array}$ \\
\hline
\end{tabular}


TABLE 3 | Continued

\begin{tabular}{|c|c|c|c|c|c|c|c|}
\hline Nucleotide & $\begin{array}{l}\text { Sequence } \\
\text { identification } \\
\text { (NCBI) }\end{array}$ & $\begin{array}{l}V v S B T \\
\text { group }\end{array}$ & $\begin{array}{l}\text { Chromosomal } \\
\text { location }\end{array}$ & selection & $\begin{array}{l}\text { Signal peptide } \\
\text { prediction, signalP } \\
4.1 \text { (position) }\end{array}$ & $\begin{array}{l}\mathrm{N} \text {-glycosylation } \\
\text { prediction } \\
\text { (Asn-X-Ser/Thr), } \\
\text { NetNGlyc } 1.0 \text { Server } \\
\text { (position and sequence) }\end{array}$ & $\begin{array}{l}\text { Subcellular } \\
\text { location } \\
\text { prediction }\end{array}$ \\
\hline & & & & & & (460 NKS) & \\
\hline & & & & & & (588 NDT) & \\
\hline & & & & & & (719 NLT) & \\
\hline \multirow[t]{2}{*}{ XM_002278414.3 } & $\begin{array}{l}\text { Subtilisin-like } \\
\text { protease SBT3.3 }\end{array}$ & vvSBT3 & 2 & $\begin{array}{l}\text { Similarity to } \\
\text { AtSBT3.3 }\end{array}$ & YES (1-35) & $\begin{array}{l}\text { YES } \\
\text { (192 NST) }\end{array}$ & $\begin{array}{l}\text { Extracellular } \\
\text { region }\end{array}$ \\
\hline & & & & & & (219 NIT) & \\
\hline \multirow[t]{3}{*}{ XM_002284065.3 } & $\begin{array}{l}\text { Subtilisin-like } \\
\text { protease }\end{array}$ & VvSBT5 & 7 & Rpv9 & YES (1-24) & $\begin{array}{l}\text { YES } \\
(172 \mathbf{N F T})\end{array}$ & $\begin{array}{l}\text { Extracellular } \\
\text { region }\end{array}$ \\
\hline & & & & & & (378 NAS) & \\
\hline & & & & & & (633 NYS) & \\
\hline \multirow[t]{5}{*}{ XM_003634104.2 } & $\begin{array}{l}\text { Subtilisin-like } \\
\text { protease SBT3.5 }\end{array}$ & vvSBT3 & 16 & $\begin{array}{l}\text { Similarity to } \\
\text { AtSBT3.3 }\end{array}$ & YES (1-27) & $\begin{array}{l}\text { YES } \\
\text { (184 NAT) }\end{array}$ & \\
\hline & & & & & & (212 NTT) & \\
\hline & & & & & & (373 NRT) & \\
\hline & & & & & & (385 NHT) & \\
\hline & & & & & & (412 NDT) & \\
\hline & & & & & & (373 NRT) & \\
\hline & & & & & & (385 NLT) & \\
\hline & & & & & & (412 NDT) & \\
\hline & & & & & & (646 NNS) & \\
\hline & & & & & & (682 NST) & \\
\hline & & & & & & (689 NVT) & \\
\hline & & & & & & (697 NST) & \\
\hline & & & & & & (722 NST) & \\
\hline \multirow[t]{4}{*}{ XM_010649370.1 } & $\begin{array}{l}\text { Subtilisin-like } \\
\text { protease SBT3.5 }\end{array}$ & vvSBT3 & 3 & $\begin{array}{l}\text { Similarity to } \\
\text { AtSBT3.3 }\end{array}$ & YES (1-27) & $\begin{array}{l}\text { YES } \\
\text { (179 NRS) }\end{array}$ & $\begin{array}{l}\text { Extracellular } \\
\text { region }\end{array}$ \\
\hline & & & & & & (362 NQT) & \\
\hline & & & & & & (407 NAT) & \\
\hline & & & & & & (651 NTT) & \\
\hline XM_010659200.1 & $\begin{array}{l}\text { Subtilisin-like } \\
\text { protease SBT5.3 } \\
\text { isoform X2 }\end{array}$ & VvSBT4 & 12 & $\begin{array}{l}\text { Located within } \\
\text { Rpv1 + Rpv13 }\end{array}$ & NO & $\begin{array}{l}\text { YES * } \\
\text { (60 NSS) }\end{array}$ & \\
\hline
\end{tabular}


TABLE 3 | Continued

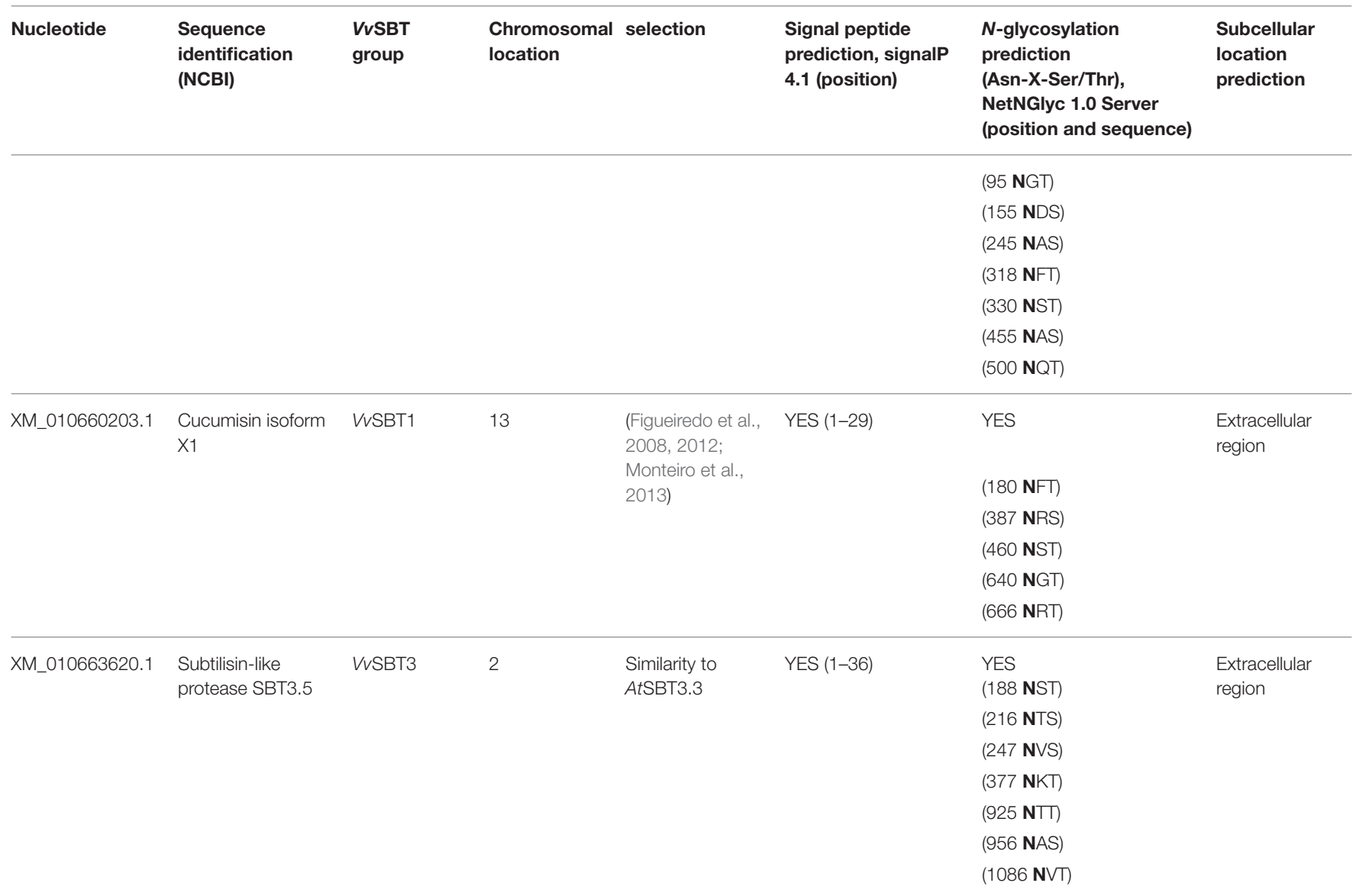

Asterisk $\left(^{\star}\right)$ indicates sequences that may not contain a signal peptide.

Two subtilases showing sequence homology with tomato P69C (XM_002275345.2 and XM_002275374.2) were upregulated at $12 \mathrm{hpi}$ and down-regulated at the other timepoints (6 and $24 \mathrm{hpi}$ ), in the resistant cultivar Regent, and not amplified in the susceptible cultivar Trincadeira. In S. tuberosum leaves, was observed the up-regulation of the expression of three genes, homologous to these two grapevine subtilase genes, after inoculation with Phytophthora infestans or elicitation with DL$\beta$-aminobutiric acid (BABA), a resistance gene inductor. This may suggest that these two genes could be pathogen induced and associated to the defense responses of resistant genotypes (Norero et al., 2016).

The subtilase XM_010660203.1 was previously identified by Figueiredo and co-workers (Figueiredo et al., 2008, 2012; Monteiro et al., 2013) as being up-regulated in the same pathosystem. This subtilase exhibited an high increase of expression in the resistant cultivar Regent at $6 \mathrm{hpi}$, but at 12 and 24 hpi the expression decreased, although it remained upregulated (6 hpi: $324.63 \pm 87.11 ; 12$ hpi: $2.26 \pm 0.38 ; 24$ hpi: 2.00 $\pm 0.34)$. In the susceptible cultivar, Trincadeira, the expression of this subtilase increased during inoculation time-course (6 hpi: $1.08 \pm 0.20 ; 12$ hpi: $2.56 \pm 0.77 ; 24$ hpi: $4.15 \pm 2.08)$. This subtilase may be considered as a strong $P$. viticola resistance associated candidate.
When comparing both incompatible (Regent) and compatible (Trincadeira) interactions it is clear that the increase in subtilase expression in Trincadeira presents a delay when compared to the resistant cultivar in which several subtilases are highly expressed 6 hpi (Figure 4). An early increase of expression of some subtilases in the incompatible interaction may be related to the successful establishment of a defense strategy against the invading pathogen.

It has been previously shown that the subtilase XM_010660203.1, annotated as a cucumisin (VvSBT1 group) was constitutively more expressed in the resistant cultivar Regent when compared to the susceptible cultivar Trincadeira, both in field and greenhouse conditions (Figueiredo et al., 2008, 2012). To access if the subtilases that are up-regulated at $6 \mathrm{hpi}$ are also constitutively expressed in resistant genotypes we have conducted a qPCR expression analysis of these 6 subtilases (XM_003634104.2, XM_003634105.2, XM_002273159.3, XM_010659200.1,XM_010660203, XM_010649370.1) in several resistant ( $V$. labrusca, $V$. rupestris, $V$. rotundifolia, $V$. riparia, and $V$. candicans) and tolerant (V. sylvestris, V. vinifera cv Regent) Vitis genotypes comparing to the constitutive expression in $V$. vinifera cv. Trincadeira (susceptible).

None of the subtilases analyzed exhibited an up-regulated constitutive expression in comparison to Trincadeira (Figure 5). 


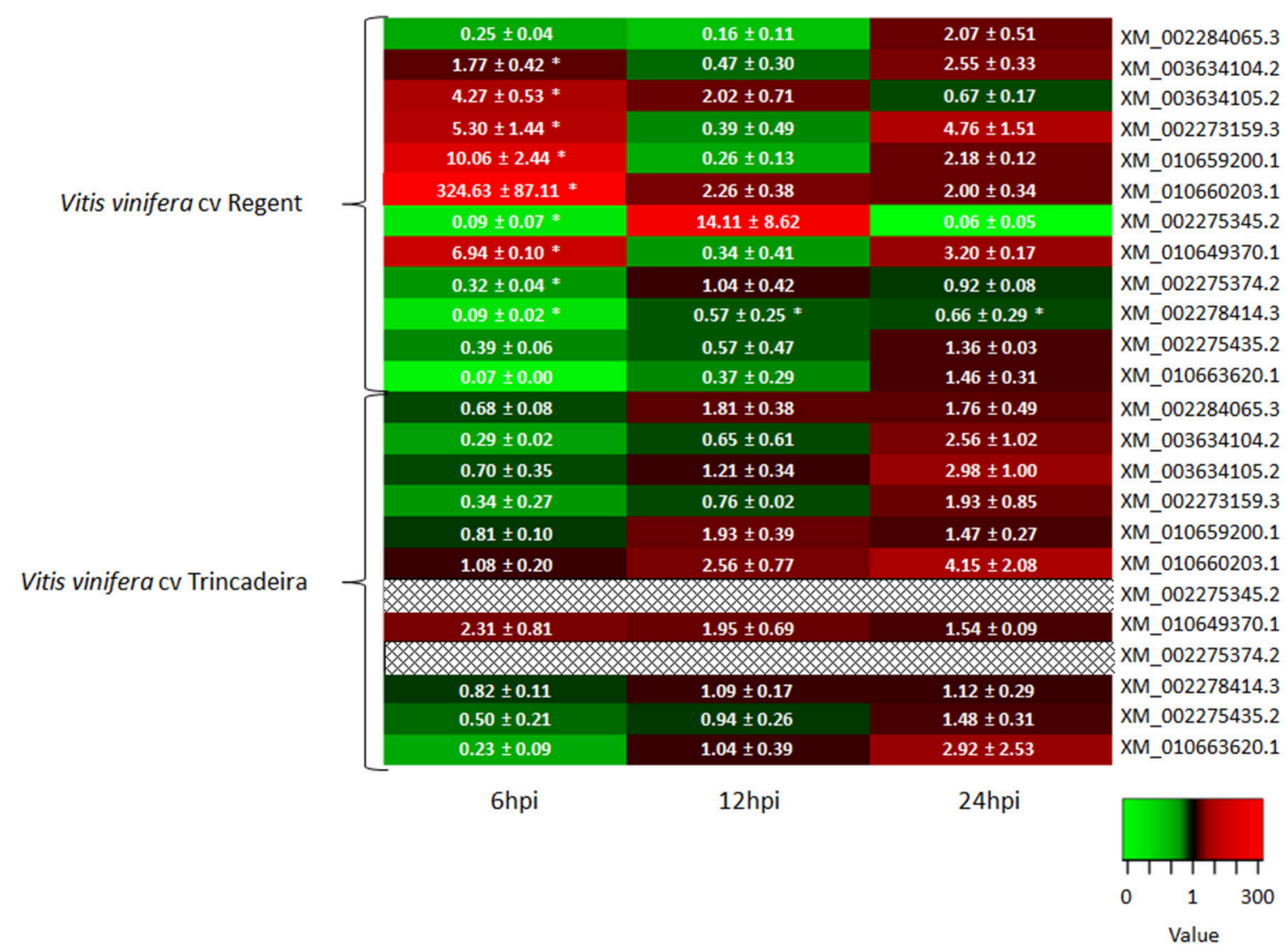

FIGURE 4 | Heatmap of the 14 grapevine subtilase expression in V. vinifera cv Regent and $V$. vinifera cv Trincadeira at 6, 12, and 24 hpi with $P$. viticola. Each column indicates a time-point (6,12, and $24 \mathrm{hpi}$ ) and each row represents a subtilase gene in the resistant grapevine genotype (Regent) or in the susceptible grapevine genotype (Trincadeira) and was colored according to the log2 ratio of expression. Green indicates lower expression, red indicates higher expression, black indicates no expression (see the color scale) and $\mathbf{X}$ indicates no amplification. Asterisks ( $\left.{ }^{*}\right)$ represent significant difference $(p \leq 0.05)$ between target and control samples (Mann-Whitney U-test; SPSS Inc., USA, V20).

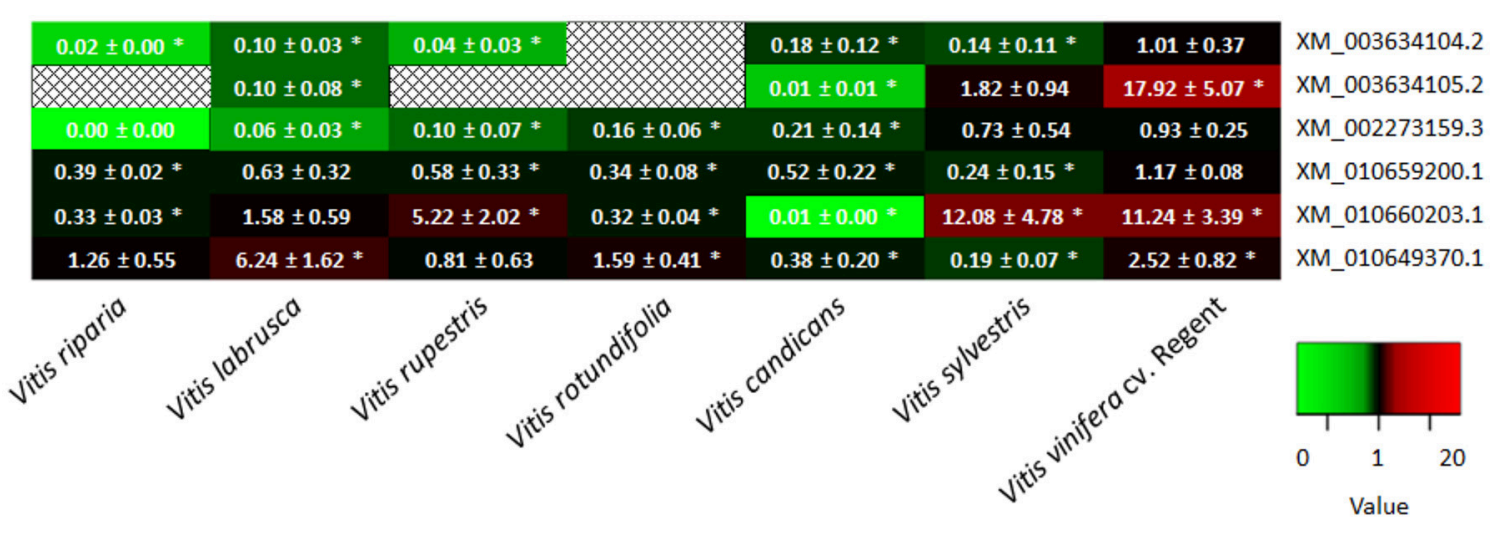

FIGURE 5 | Heatmap of the constitutive expression of 6 grapevine subtilases associated with P. viticola resistance (XM_003634104.2,

XM_003634105.2, XM_002273159.3, XM_010659200.1, XM_010660203, XM_010649370.1). Each column indicates a Vitis specie and each row represents a subtilase gene. Green indicates lower expression, red indicates higher expression, black indicates no expression (see the color scale) and $\mathrm{B}$ indicates no amplification. Asterisks $\left(^{*}\right)$ represent significant difference $(p \leq 0.05)$ between target and control samples (Mann-Whitney U-test; SPSS Inc., USA, V20). 
However, the subtilase XM_010660203.1, the cucumisin previously identified by our group, was more expressed in several resistant and tolerant species/cultivars ( $V$. labrusca: 1.58 $\pm 0.59, V$. rupestris: $5.22 \pm 2.02, V$. sylvestris: $12.08 \pm 4.78, V$. vinifera cv. Regent: $11.24 \pm 3.39$ ). Our results suggest that the expression of the majority of the grapevine subtilases analyzed may be induced by the pathogen, nonetheless the cucumisin XM_010660203.1 may be constitutively accumulated in some grapevine resistant genotypes, contributing to a rapid and strong increase of expression after pathogen inoculation.

\section{CONCLUSIONS}

This work presents the identification and characterization of the grapevine subtilase family, comprising 82 genes (20 of each are intronless), after the grapevine genome reannotation (Vitulo et al., 2014). These genes present an uneven distribution along 15 of the 19 grapevine chromosomes and encode 97 putative VvSBT proteins, due to alternative splicing. Phylogenetical analysis allowed the characterization of six groups ( $V v \mathrm{SBT} 1-V v \mathrm{SBT} 6)$ based on amino acid similarity.

Our results suggest that grapevine subtilases may exert several functions and that several grapevine subtilases may be potentially involved in pathogen defense, particularly to P. viticola. We have shown that several grapevine subtilases present sequence similarity with Arabidopsis SBT3.3 and tomato P69, some are located in the $P$. viticola resistance associated locis $(R p v)$ or are up-regulated during $P$. viticola infection. Also, the majority of subtilases are predicted to be located in the extracellular space which reinforces their putative role in the defense mechanisms against pathogens. XM_010660203.1, the cucumisin previously identified as possibly involved in the grapevine defense mechanisms (Figueiredo et al., 2008, 2012; Monteiro et al., 2013), presented the higher increase of expression after inoculation and it is constitutively expressed in several resistant grapevine genotypes, thus it may be considered a strong resistance-associated candidate. More studies must be conducted to define subtilase functions and their role on plant-pathogen interactions particularly in the grapevine resistance against $P$. viticola.

\section{REFERENCES}

Anonymous. (2000). Description List of Varieties Grapes 2000. Federal Office of Plant Varieties. Hannover: Landburh Verlog.

Antão, C. M., and Malcata, F. X. (2005). Plant serine proteases: biochemical, physiological and molecular features. Plant Physiol. Biochem. 43, 637-650. doi: 10.1016/j.plaphy.2005.05.001

Bellin, D., Peressotti, E., Merdinoglu, D., Wiedemann-Merdinoglu, S., AdamBlondon, A.-F., Cipriani, G., et al. (2009). Resistance to Plasmopara viticola in grapevine "Bianca" is controlled by a major dominant gene causing localised necrosis at the infection site. Theor. Appl. Genet. 120, 163-176. doi: 10.1007/s00122-009-1167-2

Blasi, P., Blanc, S., Wiedemann-Merdinoglu, S., Prado, E., Rühl, E. H., Mestre, P., et al. (2011). Construction of a reference linkage map of Vitis amurensis and genetic mapping of Rpv8, a locus conferring resistance to grapevine downy mildew. Theor. Appl. Genet. 123, 43-53. doi: 10.1007/s00122-011-1565-0

Bridges, C. B. (1936). THE BAR “GENE” A DUPLICATION. Science 83, 210-211. doi: $10.1126 /$ science.83.2148.210

\section{AUTHOR CONTRIBUTIONS}

AF conceived the study and planned the experiment. JF and MM performed the experiments; JF has done the bioinformatic analysis. GC and OP performed the phylogenetical analysis. AF, MS, RM, and JF performed data analysis. AF, JF, and MS wrote the manuscript. All authors have read and approved the manuscript.

\section{ACKNOWLEDGMENTS}

This work was supported by projects PEst-OE/BIA/UI4046/2014, PEst-OE/QUI/UI0612/2013, UID/MULTI/00612/2013, and grant SFRH/BPD/99712/2014 from Fundação para a Ciência e Tecnologia (FCT/MCTES/PIDDAC, Portugal), and by the European FP7 project PERSSILAA (grant agreement 610359).

\section{SUPPLEMENTARY MATERIAL}

The Supplementary Material for this article can be found online at: http://journal.frontiersin.org/article/10.3389/fpls.2016. 01783/full\#supplementary-material

\section{Supplementary Data 1 | Information about Vitis species and Vitis vinifera cultivars used in gene expression analysis of subtilase genes; $\mathbf{R}$ (resistant), T (tolerant), S (susceptible).}

\section{Supplementary Data 2 | Target and reference gene oligonucleotide sequences, amplicon length, amplification efficiency, annealing, and melting temperature are represented.}

Supplementary Data 3 | General features of grapevine subtilases. Gene locus, nucleotide, and protein accessions, VvSBT group, chromosomal location, number of intron and exons, protein predicted name, enzyme code, protein length, molecular weight, isoelectric point, domain, and Gene Ontology terms are represented.

\section{Supplementary Data 4 | Targeting prediction of the 97 grapevine subtilases using either TargetP v1.1 or PredoTar v1.3.}

Supplementary Data 5 | Information about the top five proteins that interact with all of the $\mathbf{1 4}$ grapevine subtilases selected for expression studies. STRING identifier, Uniprot ID, predicted identification and GO terms associated with the interactor protein are presented.

Brown, J. R., and Doolittle, W. F. (1995). Root of the universal tree of life based on ancient aminoacyl-tRNA synthetase gene duplications. Proc. Natl. Acad. Sci. U.S.A. 92, 2441-2445. doi: 10.1073/pnas.92.7.2441

Burland, T. (1999). "DNASTAR's lasergene sequence analysis software," in Bioinformatics Methods and Protocols Methods in Molecular Biology ${ }^{T M}$, eds S. Misener and S. Krawetz (Humana Press), 71-91. doi: 10.1385/1-59259-192$2 \% 3 \mathrm{~A} 71$

Bykova, N. V., Rampitsch, C., Krokhin, O., Standing, K. G., and Ens, W. (2006). Determination and characterization of site-specific Nglycosylation using MALDI-Qq-TOF tandem mass spectrometry: case study with a plant protease. Anal. Chem. 78, 1093-1103. doi: 10.1021/ac05 12711

Cao, J., Han, X., Zhang, T., Yang, Y., Huang, J., and Hu, X. (2014). Genome-wide and molecular evolution analysis of the subtilase gene family in Vitis vinifera. BMC Genomics 15:1116. doi: 10.1186/1471-2164-15-1116

Cedzich, A., Huttenlocher, F., Kuhn, B. M., Pfannstiel, J., Gabler, L., Stintzi, A., et al. (2009). The protease-associated domain and c-terminal extension are required for zymogen processing, sorting within the secretory pathway, 
and activity of tomato subtilase 3 (SISBT3). J. Biol. Chem. 284, 14068-14078. doi: 10.1074/jbc.M900370200

Che, P., Bussell, J. D., Zhou, W., Estavillo, G. M., Pogson, B. J., and Smith, S. M. (2010). Signaling from the endoplasmic reticulum activates brassinosteroid signaling and promotes acclimation to stress in Arabidopsis. Sci. Signal. 3:ra69. doi: $10.1126 /$ scisignal.2001140

Christ, U., and Mösinger, E. (1989). Pathogenesis-related proteins of tomato: I. Induction by Phytophthora infestans and other biotic and abiotic inducers and correlations with resistance. Physiol. Mol. Plant Pathol. 35, 53-65. doi: 10.1016/0885-5765(89)90007-6

Conesa, A., Götz, S., García-Gómez, J. M., Terol, J., Talón, M., and Robles, M. (2005). Blast2GO: a universal tool for annotation, visualization and analysis in functional genomics research. Bioinformatics 21, 3674-3676. doi: 10.1093/bioinformatics/bti610

Dhanasekaran, N., and Premkumar Reddy, E. (1998). Signaling by dual specificity kinases. Oncogene 17, 1447-1455. doi: 10.1038/sj.onc.1202251

Dixon, R., and Lamb, C. (1990). Molecular communication in interactions between plants and microbial pathogens. Annu. Rev. Plant Physiol. Plant Mol. Biol. 41, 339-367. doi: 10.1146/annurev.pp.41.060190.002011

Dodson, G., and Wlodawer, A. (1998). Catalytic triads and their relatives. Trends Biochem. Sci. 23, 347-352. doi: 10.1016/S0968-0004(98)01254-7

Duan, X., Zhang, Z., Wang, J., and Zuo, K. (2016). Characterization of a novel cotton subtilase gene GbSBT1 in response to extracellular stimulations and its role in verticillium resistance. PLOS ONE 11:e0153988. doi: 10.1371/journal.pone. 0153988

Emanuelsson, O., Nielsen, H., Brunak, S., and von Heijne, G. (2000). Predicting subcellular localization of proteins based on their N-terminal amino acid sequence. J. Mol. Biol. 300, 1005-1016. doi: 10.1006/jmbi.2000.3903

Fernández, M. B., Daleo, G. R., and Guevara, M. G. (2012). DEVDase activity is induced in potato leaves during Phytophthora infestans infection. Plant Physiol. Biochem. 61, 197-203. doi: 10.1016/j.plaphy.2012.10.007

Fernández, M. B., Daleo, G. R., and Guevara, M. G. (2015). Isolation and characterization of a Solanum tuberosum subtilisin-like protein with caspase-3 activity (StSBTc-3). Plant Physiol. Biochem. 86, 137-146. doi: 10.1016/j.plaphy.2014.12.001

Figueiredo, A., Fortes, A. M., Ferreira, S., Sebastiana, M., Choi, Y. H., Sousa, L., et al. (2008). Transcriptional and metabolic profiling of grape (Vitis vinifera L.) leaves unravel possible innate resistance against pathogenic fungi. J. Exp. Bot. 59, 3371-3381. doi: 10.1093/jxb/ern187

Figueiredo, A., Monteiro, F., Fortes, A. M., Bonow-Rex, M., Zyprian, E., Sousa, L., et al. (2012). Cultivar-specific kinetics of gene induction during downy mildew early infection in grapevine. Funct. Integr. Genomics 12, 379-386. doi: $10.1007 /$ s10142-012-0261-8

Figueiredo, A., Sebastiana, M., Martins, J., Monteiro, F., Coelho, A. V., and Pais, M. S. (2015). Early events of grapevine resistance towards downy mildew by a systems biology approach. Rev. Ciêncais Agrár. 38, 124-130.

Finn, R. D., Coggill, P., Eberhardt, R. Y., Eddy, S. R., Mistry, J., Mitchell, A. L., et al. (2016). The Pfam protein families database: towards a more sustainable future. Nucleic Acids Res. 44, D279-D285. doi: 10.1093/nar/gkv1344

Fischer, B. M., Salakhutdinov, I., Akkurt, M., Eibach, R., Edwards, K. J., Töpfer, R., et al. (2004). Quantitative trait locus analysis of fungal disease resistance factors on a molecular map of grapevine. Theor. Appl. Genet. 108, 501-515. doi: 10.1007/s00122-003-1445-3

Fischer, W., Christ, U., Baumgartner, M., Erismann, K. H., and Mösinger, E. (1989). Pathogenesis-related proteins of tomato: II. Biochemical and immunological characterization. Physiol. Mol. Plant Pathol. 35, 67-83. doi: 10.1016/0885-5765(89)90008-8

Gasteiger, E., Hoogland, C., Gattiker, A., Duvaud, S., Wilkins, M. R., Appel, R. D., et al. (2005). "Protein identification and analysis tools on the ExPASy Server," in The Proteomics Protocols Handbook, ed J. Walker (Humana Press), 571-607. doi: 10.1385/1-59259-890-0\%3A571

Gindro, K., Berger, V., Godard, S., Voinesco, F., Schnee, S., Viret, O., et al. (2012). Protease inhibitors decrease the resistance of Vitaceae to Plasmopara viticola. Plant Physiol. Biochem. 60, 74-80. doi: 10.1016/j.plaphy.2012. 07.028

Granell, A., Bellés, J. M., and Conejero, V. (1987). Induction of pathogenesisrelated proteins in tomato by citrus exocortis viroid, silver ion and ethephon. Physiol. Mol. Plant Pathol. 31, 83-90. doi: 10.1016/0885-5765(87) 90008-7
Guerreiro, A., Figueiredo, J., Sousa Silva, M., and Figueiredo, A. (2016). Linking jasmonic acid to grapevine resistance against the biotrophic oomycete Plasmopara viticola. Front. Plant Sci. 7:565. doi: 10.3389/fpls.2016.00565

Gupta, R., and Brunak, S. (2002). Prediction of glycosylation across the human proteome and the correlation to protein function. Pac. Symp. Biocomput. 7, 310-322.

Hall, T. A. (1999). "BioEdit: a user-friendly biological sequence alignment editor and analysis program for Windows 95/98/NT", in Nucleic Acids Symposium Series 41 .

Han, J.-H., Batey, S., Nickson, A. A., Teichmann, S. A., and Clarke, J. (2007). The folding and evolution of multidomain proteins. Nat. Rev. Mol. Cell Biol. 8, 319-330. doi: 10.1038/nrm2144

Hellemans, J., Mortier, G., De Paepe, A., Speleman, F., and Vandesompele, J. (2007). qBase relative quantification framework and software for management and automated analysis of real-time quantitative PCR data. Genome Biol. 8:R19.doi: 10.1186/gb-2007-8-2-r19

Jones, P., Binns, D., Chang, H.-Y., Fraser, M., Li, W., McAnulla, C., et al. (2014). InterProScan 5: genome-scale protein function classification. Bioinformatics 30, 1236-1240. doi: 10.1093/bioinformatics/btu031

Jordá, L., Coego, A., Conejero, V., and Vera, P. (1999). A genomic cluster containing four differentially regulated subtilisin-like processing protease genes is in tomato plants. J. Biol. Chem. 274, 2360-2365. doi: 10.1074/jbc.274.4.2360

Jordá, L., Conejero, V., and Vera, P. (2000). Characterization of P69E and $\mathrm{P} 69 \mathrm{~F}$, two differentially regulated genes encoding new members of the subtilisin-like proteinase family from tomato plants. Plant Physiol. 122, 67-74. doi: 10.1104/pp.122.1.67

Katoh, K., and Standley, D. M. (2013). MAFFT multiple sequence alignment software version 7: improvements in performance and usability. Mol. Biol. Evol. 30, 772-780. doi: 10.1093/molbev/mst010

Kortekamp, A., Welter, L., Vogt, S., Knoll, A., Schwander, F., Töpfer, R., et al. (2008). Identification, isolation and characterization of a CC-NBS-LRR candidate disease resistance gene family in grapevine. Mol. Breed. 22, 421-432. doi: 10.1007/s11032-008-9186-2

Kortekamp, A., and Zyprian, E. (2003). Characterization of PlasmoparaResistance in grapevine using in vitro plants. J. Plant Physiol. 160, 1393-1400. doi: 10.1078/0176-1617-01021

Liu, J.-X., and Howell, S. H. (2010a). bZIP28 and NF-Y transcription factors are activated by ER Stress and assemble into a transcriptional complex to regulate stress response genes in Arabidopsis. Plant Cell 22, 782-796. doi: $10.1105 /$ tpc. 109.072173

Liu, J.-X., and Howell, S. H. (2010b). Endoplasmic reticulum protein quality control and its relationship to environmental stress responses in plants. Plant Cell 22, 2930-2942. doi: 10.1105/tpc.110.078154

Liu, J.-X., Srivastava, R., Che, P., and Howell, S. H. (2007). Salt stress responses in Arabidopsis utilize a signal transduction pathway related to endoplasmic reticulum stress signaling: salt stress elicits ER stress response. Plant J. 51, 897-909. doi: 10.1111/j.1365-313X.2007.03195.x

Marguerit, E., Boury, C., Manicki, A., Donnart, M., Butterlin, G., Némorin, A., et al. (2009). Genetic dissection of sex determinism, inflorescence morphology and downy mildew resistance in grapevine. Theor. Appl. Genet. 118, 1261-1278. doi: 10.1007/s00122-009-0979-4

Meichtry, J., Amrhein, N., and Schaller, A. (1999). Characterization of the subtilase gene family in tomato (Lycopersicon esculentum Mill.). Plant Mol. Biol. 39, 749-760. doi: 10.1023/A:1006193414434

Merdinoglu, D., Wiedeman-Merdinoglu, S., Coste, P., Dumas, V., Haetty, S., Butterlin, G., et al. (2003). GENETIC ANALYSIS OF DOWNY MILDEW RESISTANCE DERIVED FROM MUSCADINIA ROTUNDIFOLIA. Acta Hortic. 603, 451-456. doi: 10.17660/ActaHortic.2003.603.57

Miller, M. A., Pfeiffer, W., and Schwartz, T. (2010). "Creating the CIPRES Science Gateway for inference of large phylogenetic trees," in Gateway Computing Environments Workshop (GCE), 2010.

Monteiro, F., Sebastiana, M., Pais, M. S., and Figueiredo, A. (2013). Reference gene selection and validation for the early responses to downy mildew infection in susceptible and resistant vitis vinifera cultivars. PLOS ONE 8:e72998. doi: 10.1371/journal.pone. 0072998

Moreira, F. M., Madini, A., Marino, R., Zulini, L., Stefanini, M., Velasco, R., et al. (2011). Genetic linkage maps of two interspecific grape crosses (Vitis spp.) used to localize quantitative trait loci for downy mildew resistance. Tree Genet. Genomes 7, 153-167. doi: 10.1007/s11295-010-0322-x 
Neuteboom, L. W., Veth-Tello, L. M., Clijdesdale, O. R., Hooykaas, P. J., and van der Zaal, B. J. (1999). A novel subtilisin-like protease gene from arabidopsis thaliana is expressed at sites of lateral root emergence. DNA Res. 6, 13-19. doi: $10.1093 /$ dnares/6.1.13

Norero, N. S., Castellote, M. A., de la Canal, L., and Feingold, S. E. (2016). Genomewide analyses of subtilisin-like serine proteases on Solanum tuberosum. Am. J. Potato Res. 93, 485-496. doi: 10.1007/s12230-016-9525-5

Ochßner, I., Hausmann, L., and Töpfer, R. (2016). Rpv14, a new genetic source for Plasmopara viticola resistance conferred by Vitis cinerea. VITIS - J. Grapevine Res. 55, 79-81. doi: 10.5073/vitis.2016.55.79-81

Othman, R., and Nuraziyan, A. (2010). Fruit-specific expression of papaya subtilase gene. J. Plant Physiol. 167, 131-137. doi: 10.1016/j.jplph.2009.07.015

Petersen, T. N., Brunak, S., von Heijne, G., and Nielsen, H. (2011). SignalP 4.0: discriminating signal peptides from transmembrane regions. Nat. Methods 8, 785-786. doi: 10.1038/nmeth.1701

Ramírez, V., López, A., Mauch-Mani, B., Gil, M. J., and Vera, P. (2013). An extracellular subtilase switch for immune priming in Arabidopsis. PLOS Pathog. 9:e1003445. doi: 10.1371/journal.ppat.1003445

Rautengarten, C., Steinhauser, D., Büssis, D., Stintzi, A., Schaller, A., Kopka, J., et al. (2005). Inferring hypotheses on functional relationships of genes: analysis of the arabidopsis thaliana subtilase gene family. PLoS Comput. Biol. 1:e40. doi: 10.1371/journal.pcbi.0010040

Rautengarten, C., Usadel, B., Neumetzler, L., Hartmann, J., Büssis, D., and Altmann, T. (2008). A subtilisin-like serine protease essential for mucilage release from Arabidopsis seed coats. Plant J. 54, 466-480. doi: 10.1111/j.1365-313X.2008.03437.x

Rawlings, N. D., and Salvesen, G. (eds). (2013). Handbook of Proteolytic Enzymes, 3rd Edn. Amsterdam: Elsevier/AP.

Rawlings, N. D., Waller, M., Barrett, A. J., and Bateman, A. (2014). MEROPS: the database of proteolytic enzymes, their substrates and inhibitors. Nucleic Acids Res. 42, D503-D509. doi: 10.1093/nar/gkt953

Rose, R., Schaller, A., and Ottmann, C. (2010). Structural features of plant subtilases. Plant Signal. Behav. 5, 180-183. doi: 10.4161/psb.5.2.11069

Schaller, A., and Ryan, C. A. (1994). Identification of a 50-kDa systemin-binding protein in tomato plasma membranes having Kex2p-like properties. Proc. Natl. Acad. Sci. U.S.A. 91, 11802-11806. doi: 10.1073/pnas.91.25.11802

Schaller, A., Stintzi, A., and Graff, L. (2012). Subtilases - versatile tools for protein turnover, plant development, and interactions with the environment. Physiol. Plant. 145, 52-66. doi: 10.1111/j.1399-3054.2011.01529.x

Schwander, F., Eibach, R., Fechter, I., Hausmann, L., Zyprian, E., and Töpfer, R. (2011). Rpv10: a new locus from the Asian Vitis gene pool for pyramiding downy mildew resistance loci in grapevine. Theor. Appl. Genet. 124, 163-176. doi: 10.1007/s00122-011-1695-4

Siezen, R. J. (1996). Subtilases: subtilisin-like serine proteases. Adv. Exp. Med. Biol. 379, 75-93. doi: 10.1007/978-1-4613-0319-0_9

Siezen, R. J., de Vos, W. M., Leunissen, J. A., and Dijkstra, B. W. (1991). Homology modelling and protein engineering strategy of subtilases, the family of subtilisin-like serine proteinases. Protein Eng. 4, 719-737. doi: $10.1093 /$ protein/4.7.719

Siezen, R. J., and Leunissen, J. A. (1997). Subtilases: the superfamily of subtilisinlike serine proteases. Protein Sci. 6, 501-523. doi: 10.1002/pro.5560060301

Siezen, R. J., Renckens, B., and Boekhorst, J. (2007). Evolution of prokaryotic subtilases: genome-wide analysis reveals novel subfamilies with different catalytic residues. Proteins 67, 681-694. doi: 10.1002/prot.21290

Small, I., Peeters, N., Legeai, F., and Lurin, C. (2004). Predotar: a tool for rapidly screening proteomes for $\mathrm{N}$-terminal targeting sequences. Proteomics 4, 1581-1590. doi: 10.1002/pmic.200300776

Szklarczyk, D., Franceschini, A., Wyder, S., Forslund, K., Heller, D., HuertaCepas, J., et al. (2014). STRING v10: protein-protein interaction networks, integrated over the tree of life. Nucleic Acids Res. 43, D447-D452. doi: 10.1093/nar/gku1003

Tanaka, H., Onouchi, H., Kondo, M., Hara-Nishimura, I., Nishimura, M., Machida, C., et al. (2001). A subtilisin-like serine protease is required for epidermal surface formation in Arabidopsis embryos and juvenile plants. Development 128, 4681-4689.

Tornero, P., Conejero, V., and Vera, P. (1996). Primary structure and expression of a pathogen-induced protease (PR-P69) in tomato plants: similarity of functional domains to subtilisin-like endoproteases. Proc. Natl. Acad. Sci. U.S.A. 93, 6332-6337. doi: 10.1073/pnas.93.13.6332
Tornero, P., Conejero, V., and Vera, P. (1997). Identification of a new pathogeninduced member of the subtilisin-like processing protease family from plants. J. Biol. Chem. 272, 14412-14419. doi: 10.1074/jbc.272.22.14412

Tripathi, L. P., and Sowdhamini, R. (2006). Cross genome comparisons of serine proteases in Arabidopsis and rice. BMC Genomics 7:200. doi: 10.1186/1471-2164-7-200

Unger, S., Büche, C., Boso, S., and Kassemeyer, H.-H. (2007). The course of colonization of two different vitis genotypes by plasmopara viticola indicates compatible and incompatible host-pathogen interactions. Phytopathology 97, 780-786. doi: 10.1094/PHYTO-97-7-0780

Vandesompele, J., De Preter, K., Pattyn, F., Poppe, B., Van Roy, N., De Paepe, A., et al. (2002). Accurate normalization of real-time quantitative RT-PCR data by geometric averaging of multiple internal control genes. Genome Biol. 3:research0034. doi: 10.1186/gb-2002-3-7-research0034

Vartapetian, A. B., Tuzhikov, A. I., Chichkova, N. V., Taliansky, M., and Wolpert, T. J. (2011). A plant alternative to animal caspases: subtilisin-like proteases. Cell Death Differ. 18, 1289-1297. doi: 10.1038/cdd.2011.49

Venuti, S., Copetti, D., Foria, S., Falginella, L., Hoffmann, S., Bellin, D., et al. (2013). Historical introgression of the downy mildew resistance gene Rpv12 from the asian species Vitis amurensis into grapevine varieties. PLOS ONE 8:e61228. doi: 10.1371/journal.pone.0061228

Vera, P., and Conejero, V. (1988). Pathogenesis-related proteins of tomato P-69 as an alkaline endoproteinase. Plant Physiol. 87, 58-63. doi: 10.1104/pp.87.1.58

Vera, P., Yago, J. H., and Conejero, V. (1989). Immunogold localization of the citrus exocortis viroid-induced pathogenesis-related proteinase P69 in tomato leaves. Plant Physiol. 91, 119-123. doi: 10.1104/pp.91.1.119

Vitulo, N., Forcato, C., Carpinelli, E. C., Telatin, A., Campagna, D., D’Angelo, M., et al. (2014). A deep survey of alternative splicing in grape reveals changes in the splicing machinery related to tissue, stress condition and genotype. BMC Plant Biol. 14:99. doi: 10.1186/1471-2229-14-99

Von Groll, U., Berger, D., Altmann, T. (2002). The subtilisin-like serine protease SDD1 mediates cell-to-cell signaling during Arabidopsis stomatal development. Plant Cell Online 14, 1527-1539. doi: 10.1105/tpc. 001016

Welter, L. J., Göktürk-Baydar, N., Akkurt, M., Maul, E., Eibach, R., Töpfer, R., et al. (2007). Genetic mapping and localization of quantitative trait loci affecting fungal disease resistance and leaf morphology in grapevine (Vitis vinifera). Mol. Breed. 20, 359-374. doi: 10.1007/s11032-007-9097-7

Weng, K., Li, Z.-Q., Liu, R.-Q., Wang, L., Wang, Y.-J., and Xu, Y. (2014). Transcriptome of erysiphe necator-infected Vitis pseudoreticulata leaves provides insight into grapevine resistance to powdery mildew. Hortic. Res. 1, 14049. doi: 10.1038/hortres.2014.49

Wiedemann-Merdinoglu, S., Prado, E., Coste, P., Dumas, V., Butterlin, G., Bouquet, A., et al. (2006). "Genetic analysis of resistance to downy mildew from Muscadinia rotundifolia," in 9th International Conference on Grape Genetics Breeding (Udine).

Yan, H., Dai, X., Feng, K., Ma, Q., and Yin, T. (2016). IGDD: a database of intronless genes in dicots. BMC Bioinformatics 17:289. doi: 10.1186/s12859-016-1148-9

Yoshida, K. T., and Kuboyama, T. (2001). A subtilisin-like serine protease specifically expressed in reproductive organs in rice. Sex. Plant Reprod. 13, 193-199. doi: 10.1007/s004970000059

Zhang, J. (2003). Evolution by gene duplication: an update. Trends Ecol. Evol. 18, 292-298. doi: 10.1016/S0169-5347(03)00033-8

Zhao, C., Johnson, B. J., Kositsup, B., and Beers, E. P. (2000). Exploiting secondary growth in Arabidopsis. Construction of xylem and bark cDNA libraries and cloning of three xylem endopeptidases. Plant Physiol. 123, 1185-1196. doi: $10.1104 /$ pp.123.3.1185

Conflict of Interest Statement: The authors declare that the research was conducted in the absence of any commercial or financial relationships that could be construed as a potential conflict of interest.

Copyright (C) 2016 Figueiredo, Costa, Maia, Paulo, Malhó, Sousa Silva and Figueiredo. This is an open-access article distributed under the terms of the Creative Commons Attribution License (CC BY). The use, distribution or reproduction in other forums is permitted, provided the original author(s) or licensor are credited and that the original publication in this journal is cited, in accordance with accepted academic practice. No use, distribution or reproduction is permitted which does not comply with these terms. 